\title{
QUEEN'S
UNIVERSITY
BELFAST
}

\section{Isobaric and Isochoric Heat Capacities of Imidazolium-Based and Pyrrolidinium-Based Ionic Liquids as Function of Temperature: Modeling of Isobaric Heat Capacity}

Zorebski, E., Zorębski, M., Dzida, M., Goodrich, P., \& Jacquemin, J. (2017). Isobaric and Isochoric Heat Capacities of Imidazolium-Based and Pyrrolidinium-Based lonic Liquids as Function of Temperature: Modeling of Isobaric Heat Capacity. Industrial and Engineering Chemistry Research.

https://doi.org/10.1021/acs.iecr.6b04780

Published in:

Industrial and Engineering Chemistry Research

Document Version:

Publisher's PDF, also known as Version of record

Queen's University Belfast - Research Portal:

Link to publication record in Queen's University Belfast Research Portal

\section{Publisher rights}

Copyright 2017 the authors.

This is an open access article published under a Creative Commons Attribution (CC-BY) License, which permits unrestricted use, distribution and reproduction in any medium, provided the author and source are cited.

\section{General rights}

Copyright for the publications made accessible via the Queen's University Belfast Research Portal is retained by the author(s) and / or other copyright owners and it is a condition of accessing these publications that users recognise and abide by the legal requirements associated with these rights.

Take down policy

The Research Portal is Queen's institutional repository that provides access to Queen's research output. Every effort has been made to ensure that content in the Research Portal does not infringe any person's rights, or applicable UK laws. If you discover content in the

Research Portal that you believe breaches copyright or violates any law, please contact openaccess@qub.ac.uk. 


\title{
Isobaric and Isochoric Heat Capacities of Imidazolium-Based and Pyrrolidinium-Based Ionic Liquids as a Function of Temperature: Modeling of Isobaric Heat Capacity
}

\author{
Edward Zorębski, ${ }^{\dagger}{ }^{\dagger}$ Michał Zorębski, ${ }^{\dagger}$ Marzena Dzida, $^{\dagger}$ Peter Goodrich, $^{\ddagger}$ and Johan Jacquemin ${ }^{\ddagger}, \S$ \\ ${ }^{\dagger}$ Institute of Chemistry, University of Silesia, Szkolna 9, 40-006 Katowice, Poland \\ ${ }^{\ddagger}$ QUILL Research Centre, School of Chemistry and Chemical Engineering, Queen’s University Belfast, David Keir Building, Belfast, \\ Northern Ireland BT9 5AG, United Kingdom \\ ${ }^{\S}$ Laboratoire PCM2E, Université François Rabelais, Parc de Grandmont 37200 Tours, France
}

Supporting Information

ABSTRACT: The isobaric and isochoric heat capacities of seven 1-alkyl-3-methylimidazolium bis(trifluoromethylsulfonyl)imides, two 1-alkyl-1-methylpyrrolidinium bis(trifluoromethylsulfonyl)imides, and two bis(1-alkyl-3-methylimidazolium) tetrathiocyanatocobaltates were determined at atmospheric pressure in the temperature range from 293.15 to $323.15 \mathrm{~K}$. The isobaric heat capacities were determined by means of differential scanning calorimetry, whereas isochoric heat capacities were determined along with isothermal compressibilities indirectly by means of the acoustic method from the speed of sound and density measure-

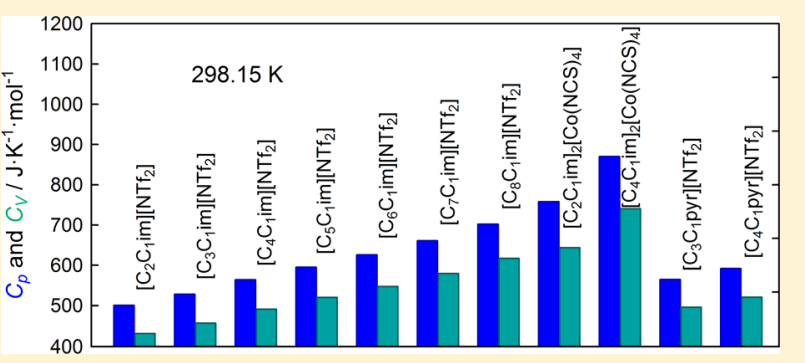
ments. Based on the experimental data, as expected, the isobaric heat capacity increases linearly with increasing alkyl chain length in the cation of 1-alkyl-3-methylimidazolium bis(trifluoromethylsulfonyl)imides and no odd and even carbon number effect is observed. After critical comparison of the obtained data with the available literature data, the most reliable values are recommended. It has been also shown that, although the COSMOthermX calculations underestimated the isobaric heat capacity values whatever the temperature and the ionic liquid structure, the approach used during this work may be applied to estimate physical properties of non-single-charged ions as well. Additionally, based on the speeds of sound the thermal conductivities were calculated using a modified Bridgman relation.

\section{INTRODUCTION}

Although heat capacities (both isobaric and isochoric) belong to the very important thermophysical properties of matter ${ }^{1}$ and their ratio gives the equally important adiabatic index, reports about both heat capacities are rather limited. ${ }^{2-5}$ Both heat capacities are measurable state functions, but while the isobaric heat capacity is the quantity of interest mainly from a practical point of view, the isochoric heat capacity is the quantity needed in more theoretically oriented works (isochoric values are indispensable for the better understanding of processes on the molecular level). Moreover, while the reported values of the isobaric heat capacities of liquids are obtained by direct calorimetric determination, the relatively scarce values of isochoric heat capacities are for the most part obtained indirectly by the use of the acoustic method. This indirect method is attractive because calorimetric determination of isochoric heat capacities of liquids in standard conditions is still very difficult. ${ }^{6,7}$

The isobaric heat capacity, which is a second derivative of Gibbs free energy $G$ with respect to the temperature, is one of the main extensive measurable thermodynamic quantities. Accurate isobaric heat capacity values are needed in many areas of physics, chemistry, and engineering. As ionic liquids
(ILs) have been reported as alternative fluids for heat transfer or heat storage media, ${ }^{8-11}$ prior knowledge of their isobaric heat capacities as a function of temperature is crucial to assess their potential as solvents in any applications where heat flux can be present. $^{12}$ While other thermal properties such as melting point and glass temperature are frequently reported for a wide set of ILs with various structures, only a limited number of isobaric heat capacity data sets have been reported in the literature. Furthermore, significant deviations between published data are generally observed. For example, a deviation of up to $20 \%$ is observed between published data in the case of the benchmark IL 1-butyl-1-methylpyrrolidinium bis(trifluoromethylsulfonyl)imide. ${ }^{13,14}$ Although such a situation is rather uncommon for molecular solvents, in the case of ILs such deviations are not especially surprising as significant differences between various data sets are also observed for many other thermophysical and physicochemical properties. ${ }^{15}$ According to Nieto de Castro, ${ }^{15}$ a number of factors influence

Received: December 12, 2016

Revised: January 26, 2017

Accepted: February 1, 2017

Published: February 1, 2017 
Table 1. Sample Table

\begin{tabular}{lllcccc}
\multicolumn{1}{c}{ liquid } & CAS Number & supplier & $\mathrm{M} / \mathrm{g} \cdot \mathrm{mol}^{-1}$ & mass fraction purity & water/ppm & halides $/ \mathrm{ppm}$ \\
{$\left[\mathrm{C}_{2} \mathrm{C}_{1} \mathrm{im}\right]\left[\mathrm{NTf}_{2}\right]$} & $174899-82-2$ & Iolitec & 391.31 & $>0.995$ & $50^{c} / 290^{d}$ & $<100^{c}$ \\
{$\left[\mathrm{C}_{3} \mathrm{C}_{1} \mathrm{im}\right]\left[\mathrm{NTf} f_{2}\right]$} & $216299-72-8$ & QUILL & 405.34 & $0.9995^{a}$ & $71^{d}$ & $<5^{f}$ \\
{$\left[\mathrm{C}_{4} \mathrm{C}_{1} \mathrm{im}\right]\left[\mathrm{NTf}_{2}\right]$} & $174899-83-3$ & QUILL & 419.37 & $0.9995^{a}$ & $178^{d}$ & $<5^{f}$ \\
{$\left[\mathrm{C}_{5} \mathrm{C}_{1} \mathrm{im}\right]\left[\mathrm{NTf}_{2}\right]$} & $280779-53-5$ & QUILL & 433.39 & $0.9995^{a}$ & $194^{d}$ & $<5^{f}$ \\
{$\left[\mathrm{C}_{6} \mathrm{C}_{1} \mathrm{im}\right]\left[\mathrm{NTf} f_{2}\right]$} & $382150-50-7$ & QUILL & 447.42 & $0.9995^{a}$ & $92^{d}$ & $<5^{f}$ \\
{$\left[\mathrm{C}_{7} \mathrm{C}_{1} \mathrm{im}\right]\left[\mathrm{NTf} f_{2}\right]$} & $425382-14-5$ & Iolitec & 461.446 & $>0.99$ & $80^{c} / 210^{d}$ & $<100^{c}$ \\
{$\left[\mathrm{C}_{8} \mathrm{C}_{1} \mathrm{im}\right]\left[\mathrm{NTf} f_{2}\right]$} & $178631-04-4$ & Iolitec & 475.47 & $>0.99$ & $64^{c} / 310^{d}$ & $<100^{c}$ \\
{$\left[\mathrm{C}_{2} \mathrm{C}_{1} \mathrm{im}\right]_{2}\left[\mathrm{Co}(\mathrm{NCS})_{4}\right]$} & $1255925-80-4$ & Rostock & 513.59 & $\sim 0.99^{b}$ & $300^{e}$ & $\mathrm{nd}^{g}$ \\
{$\left[\mathrm{C}_{4} \mathrm{C}_{1} \mathrm{im}\right]_{2}\left[\mathrm{Co}(\mathrm{NCS})_{4}\right]$} & $1245942-47-5$ & Rostock & 569.70 & $\sim 0.99^{b}$ & $300^{e}$ & $\mathrm{nd}^{g}$ \\
{$\left[\mathrm{C}_{3} \mathrm{C}_{1} \mathrm{pyr}\right]\left[\mathrm{NTf}_{2}\right]$} & $223437-05-6$ & Iolitec & 408.38 & $>0.99$ & $100^{c} / 46^{d}$ & $<100^{c}$ \\
{$\left[\mathrm{C}_{4} \mathrm{C}_{1} \mathrm{pyr}\right]\left[\mathrm{NTf}_{2}\right]$} & $223437-11-4$ & Iolitec & 422.41 & $>0.99$ & $100^{c} / 370^{d}$ & $<100^{c}$
\end{tabular}

${ }^{a 1} \mathrm{H}$ and ${ }^{13} \mathrm{C}$ NMR. ${ }^{b}$ Estimated according to analysis in ref $24 .{ }^{c}$ Declared by supplier. ${ }^{d}$ Coulometric Karl Fischer titration, TitroLine 7500. ${ }^{e}$ Estimated in ref 20 from volumetric Karl Fischer titration. ${ }^{f}$ Below detection limit by $\mathrm{AgNO}_{3}$ titration. ${ }^{g}$ Not determined.

the uncertainty of the measured data. These can be divided in two main categories: (i) sample purity and its chemical characteristics, and (ii) instrumentation problems. Thus, a study of heat capacities of ILs, similar to all thermophysical properties, should follow a strategic procedure to control the purity of the samples (best both before and after the measurements) as well as a careful choice of the experimental method and procedures employed. ${ }^{16}$ According to the literature data, differential scanning calorimetry (DSC) is the most popular method for determining the heat capacities of ILs. ${ }^{17}$ Apart from differences in IL sample purity, the DSC must be carefully calibrated and the measurement procedure must be carefully planned and executed for minimalizing the overall experimental uncertainty.

Although the series of 1-alkyl-3-methylimidazolium bis(trifluoromethylsulfonyl)imides, denoted as $\left[\mathrm{C}_{n} \mathrm{C}_{1} \mathrm{im}\right]\left[\mathrm{NTf}_{2}\right]$, is the most investigated family of ILs, the literature reveals that very limited heat capacity data are available especially for ILs presenting odd carbon numbers in the alkyl chain on the cation. For example, in the cases of $\left[\mathrm{C}_{5} \mathrm{C}_{1} \mathrm{im}\right]\left[\mathrm{NTf}_{2}\right]$ and $\left[\mathrm{C}_{7} \mathrm{C}_{1} \mathrm{im}\right]$ $\left[\mathrm{NTf}_{2}\right]$, to the best of our knowledge, only one-point data sets exist, ${ }^{18}$ and in the case of $\left[\mathrm{C}_{3} \mathrm{C}_{1} \mathrm{im}\right]\left[\mathrm{NTf}_{2}\right]$, apart from two onepoint data sets ${ }^{18,19}$ only one polythermal data set is reported, ${ }^{9}$ to date. In addition, only a few data sets have been published for the analogous family 1-alkyl-1-methylpyrrolidinium bis(trifluoromethylsulfonyl)imides, ${ }^{17}$ denoted as $\left[\mathrm{C}_{n} \mathrm{C}_{1}\right.$ pyr $]$ $\left[\mathrm{NTf}_{2}\right]$, even if these ILs are also popular and very interesting from both practical and fundamental points of view. No data exists for the dicationic paramagnetic bis(1-alkyl-3-methylimidazolium) tetrathiocyanocobaltates, denoted as $\left[\mathrm{C}_{n} \mathrm{C}_{1} \mathrm{im}\right]_{2}[\mathrm{Co}-$ $\left.(\mathrm{NCS})_{4}\right]$, which have been recently proposed as potential hydraulic fluids ${ }^{20}$ and for which the dynamic crossover was not observed in the region of $1.2-1.5 T_{\mathrm{g}}^{21}$ (where $T_{\mathrm{g}}$ is the glass transition temperature).

In this paper, we investigate the isobaric heat capacities at atmospheric pressure for seven $\left[\mathrm{C}_{n} \mathrm{C}_{1} \mathrm{im}\right]\left[\mathrm{NTf}_{2}\right]$ with $n=2-8$, two $\left[\mathrm{C}_{n} \mathrm{C}_{1} \mathrm{im}\right]_{2}\left[\mathrm{Co}(\mathrm{NCS})_{4}\right]$ with $n=2$ or 4 , and two $\left[\mathrm{C}_{n} \mathrm{C}_{1}\right.$ pyr $]\left[\mathrm{NTf}_{2}\right]$ with $n=3$ or 4 , in the temperature range from 293.15 to $323.15 \mathrm{~K}$ at atmospheric pressure. Therein, the effect of cation and/or anion structure, as well as the effect of the alkyl chain length of the cation, on the heat capacity is analyzed. Moreover, a critical analysis of the available literature data was investigated to recommend the most reliable isobaric heat capacity values for the above-mentioned imidazolium- and pyrrolidinium-based ILs. Based on the experimental molar isobaric heat capacities, the isochoric molar heat capacities and adiabatic indices are determined by means of the indirect acoustic method. The acoustic method was also used to calculate thermal conductivity values. For these reasons, the supplementary density and speed of sound measurements for $\left[\mathrm{C}_{7} \mathrm{C}_{1} \mathrm{im}\right]\left[\mathrm{NTf}_{2}\right], \quad\left[\mathrm{C}_{n} \mathrm{C}_{1} \mathrm{im}\right]_{2}\left[\mathrm{Co}(\mathrm{NCS})_{4}\right](n=2,4)$, and $\left[\mathrm{C}_{n} \mathrm{C}_{1} \mathrm{pyr}\right]\left[\mathrm{NTf}_{2}\right](n=3,4)$ are performed. Lastly, the predictive capability of the Preiss et al. ${ }^{22}$ method for estimation of the molar isobaric heat capacity values is also analyzed.

\section{MATERIALS AND METHODS}

2.1. Chemicals. The origins of the 11 ILs along with the two main impurities (water and halide contents) which have the largest impact on the physicochemical properties are listed in Table 1. Five samples were commercially obtained from Iolitec (Germany), while the remaining were synthesized in the QUILL Centre (Belfast) or at the University of Rostock. In the case of the QUILL samples, additional $\mathrm{Li}$ analysis reported previously showed $\mathrm{Li}$ content not greater than $34 \mathrm{ppm}^{23}$ Details about the syntheses, purification, and storage of the noncommercial samples can be found elsewhere. ${ }^{23,24}$ In the cases of the commercial samples and the QUILL samples, prior to measurements, the water content was determined using the Karl Fischer method. If necessary, the samples were dried and degassed under low pressure at temperatures not exceeding 343 K.

The possibility of sample contamination with water during the isobaric heat capacity measurement procedure was checked by probing the water content directly before and after measurement. In the cases of $\left[\mathrm{C}_{3} \mathrm{C}_{1} \mathrm{im}\right]\left[\mathrm{NTf}_{2}\right]$ and $\left[\mathrm{C}_{7} \mathrm{C}_{1} \mathrm{im}\right]$ $\left[\mathrm{NTf}_{2}\right]$, the water contents after measurements were 164 and 270 ppm, respectively. Thus, in comparison to water contents before the measurements (Table 1 ), the measuring procedure leads to insignificant changes in water contents only.

2.2. Heat Capacity Measurements. The isobaric heat capacities were measured using a modified differential temperature-scanning microcalorimeter which has been already previously described. ${ }^{25}$ The main part of the microcalorimeter is a semiconductor differential heat flux detector of the TianCalvet type. The detector is placed in a metallic block in which temperature is digitally controlled within $\pm 0.5 \times 10^{-3} \mathrm{~K}$. A heating-cooling shield surrounds the calorimetric block; the temperature here is controlled by another digital control loop within $\pm 10 \times 10^{-3} \mathrm{~K}$. The time constant of the DSC used is equal to $9.2 \mathrm{~s}$. The cooling is performed with a thermofluid (Huber M90) circulated with a stepwise controlled pump. The reference and measuring vessels (ca. $3 \mathrm{~mL}$ constant volume) 
were made from Hastelloy $\mathrm{C} 22$. As the reference vessel the full metal cylinder was used, whereas the thickness of the measuring vessel walls was $0.2 \mathrm{~mm}$. The vessel was always sealed with a Viton O-ring, and the liquid sample volume was $2.75 \mathrm{~mL}$ in each case. To avoid or at least minimize any effects of change in surface contact of the measuring cell with the calorimeter's furnace, the measuring cell was always exactly identically oriented. The samples of ca. 3.3-4.1 g were prepared by mass (precision $\pm 6 \times 10^{-7} \mathrm{~kg}$ ) using an OHAUS balance (DV215CD). Every time before a proper measurement, the sample was heated in the measuring vessel for a final degassing. To avoid the possible effect of the "thermal history" of the samples, ${ }^{26}$ the samples were not treated in any other manner. The heat capacities have been determined using the standard procedure "continuous with reference". 27 The same temperature program known also as the three-step method (i.e., (i) isothermal phase $\left(5 \times 10^{3} \mathrm{~s}\right)$ at starting temperature, (ii) temperature scanning at a rate of $1 \mathrm{mK} \cdot \mathrm{s}^{-1}$, and (iii) isothermal phase $\left(5 \times 10^{3} \mathrm{~s}\right)$ at final temperature $)$ has been applied to the empty sample vessel, the reference sample, and the measured sample. The initial temperature of the heating-cooling shield was always set to $283.15 \mathrm{~K}$, i.e., $5 \mathrm{~K}$ lower than the initial temperature of the calorimetric block. As a reference standard 1-butanol (Aldrich, anhydrous, mass fraction purity 0.995, SureSeal) was used and the values reported in ref 28 were used as reference values. In order to check the reliability of the heat capacity measurements, the calorimeter was also tested by measurements performed with $n$-hexane and benzene (POCh, Poland, mass fraction purity 0.999) under the same experimental conditions. The test runs (in the temperature range from 293.15 to $323.15 \mathrm{~K}$ ) showed that for $n$-hexane the relative deviations of the obtained experimental data compared to the literature values reported in ref 29 are between -0.45 and $+0.15 \%$ (absolute average relative deviation (AARD) is equal to $0.25 \%$ ).

$$
\text { AARD }=100 N^{-1} \sum_{i=1}^{N} \mathrm{I}\left(y_{\text {lit }}-y_{\exp }\right) / y_{\exp } \mid
$$

where $N$ is the number of data and $y$ denotes here the molar isobaric heat capacity $C_{p}$. For benzene, the suitable deviations are between -0.11 and $+0.09 \%$ ( $\mathrm{AARD}=0.08 \%$ ) for the literature values reported in ref 30 . During all experiments, the temperature fluctuation in the air-conditioned laboratory did not exceed $\pm 1 \mathrm{~K}$. Based on the calibration procedure, test runs, and measurement procedure, and neglecting vapor correction, the expanded uncertainty (coverage factor $k=2$, confidence level 0.95 ) of the isobaric heat capacity values obtained in this work for the studied ILs was estimated to be $\pm 1 \%$.

2.3. Density Measurements. Densities were measured using a vibrating-tube densimeter DMA $5000 \mathrm{M}$ (Anton Paar) or density and sound analyzer DSA $5000 \mathrm{M}$ (Anton Paar); the latter was used only in the case of $\left[\mathrm{C}_{7} \mathrm{C}_{1} \mathrm{im}\right]\left[\mathrm{NTf}_{2}\right]$. In each case, an automatic viscosity correction was made. The devices were calibrated with dry air and redistilled water which was also freshly degassed (by boiling) before using. The densities were measured in the temperature ranges 288.15-363.15 $\mathrm{K}$ and 293.15-343.15 K, respectively. The standard uncertainty was $\pm 0.05 \mathrm{~kg} \cdot \mathrm{m}^{-3}$.

2.4. Speed of Sound Measurements. Similarly, as in previous work, ${ }^{23}$ the speed of sound measurements were performed mostly using a pulse-echo-overlap (PEO) method. In this work, two homemade PEO sets were used: (i) with a single transmitting-receiving transducer operating at a frequency of $2 \mathrm{MHz}$ and an acoustic mirror, ${ }^{23}$ or (ii) with two transducers operating also at a frequency of $2 \mathrm{MHz}{ }^{31}$ Here, the great advantage is the narrow-band technique as dispersion of the ultrasound velocity in some ILs can be present already at several megahertz, for example in the case of $\left[\mathrm{C}_{4} \mathrm{C}_{1} \mathrm{im}\right]_{2}\left[\mathrm{Co}(\mathrm{NCS})_{4}\right]$ at 7 and $10 \mathrm{MHz}$ at 293.15 and 298.15 $\mathrm{K}$, respectively. ${ }^{23}$ In such cases, the use of the wide-band technique (developed for nondispersive materials and adopted usually in commercial setups) is obviously groundless and can be a source of experimental errors (a concise comparison of both techniques can be found elsewhere ${ }^{32}$ ). For the determination of the acoustic path lengths, water was used as the reference liquid and the standard speed of sound values reported by Del Grosso and Mader ${ }^{33}$ were applied. Before use the water was prepared as for density measurements, i.e., redistilled water was freshly degassed by boiling; the prepared water showed an electrolytic conductivity of $1 \times 10^{-4} \mathrm{~S} \cdot \mathrm{m}^{-1}$ at $T=298.15 \mathrm{~K}$. A cascade thermostat unit was used for temperature stabilization, and an Ertco Hart 850 thermometer with Pt 100 sensor (NIST certificate) was used for temperature measurements (uncertainty $\pm 5 \times 10^{-2} \mathrm{~K}$ at resolution $\pm 1 \times$ $10^{-3} \mathrm{~K}$ ). For both PEO sets, the standard uncertainty of the measured speeds of sound was $\pm 0.5 \mathrm{~m} \cdot \mathrm{s}^{-1}$. The speeds of sound were measured in the temperature range of about 293$318 \mathrm{~K}$.

Moreover, in the case of $\left[\mathrm{C}_{7} \mathrm{C}_{1} \mathrm{im}\right]\left[\mathrm{NTf}_{2}\right]$ the speeds of sound were measured using the commercial apparatus DSA $5000 \mathrm{M}$ in the temperature range $293.15-343.15 \mathrm{~K}$. As in the case of the PEO sets, the DSA $5000 \mathrm{M}$ measuring cell (with transducers operating at frequency $3 \mathrm{MHz}$ ) was also calibrated with water. The apparatus was also checked with 1,2-ethanediol (Fluka, anhydrous, mass fraction purity 0.995); the deviation (at $298.15 \mathrm{~K}$ ) between the obtained experimental value and a previously reported value ${ }^{31}$ is $-0.36 \mathrm{~m} \cdot \mathrm{s}^{-1}$. Thus, the difference is below that declared by the manufacturer, an uncertainty of $\pm 0.5 \mathrm{~m} \cdot \mathrm{s}^{-1}$. Although in this apparatus the wide-band technique is adopted, the reported values for $\left[\mathrm{C}_{7} \mathrm{C}_{1} \mathrm{im}\right]\left[\mathrm{NTf}_{2}\right]$ can be treated as the thermodynamic speeds of sound because the ultrasound velocity relaxation will most probably start above $20 \mathrm{MHz}$ at $293.15 \mathrm{~K}$, as can be supposed from recently reported ultrasound investigations of a series of $\left[\mathrm{C}_{n} \mathrm{C}_{1} \mathrm{im}\right]$ $\left[\mathrm{NTf}_{2}\right]$ ILs. $^{23}$ Moreover, it should be noted that with the increasing temperature the above-mentioned frequency should also increase quickly. ${ }^{23}$

The molar masses are reported in terms of the 2001 IUPAC relative atomic masses. The temperature scale used is the ITS90 , and all measurements are made at atmospheric pressure $p_{0}$ $=0.101 \mathrm{MPa}$.

2.5. Modeling. Isobaric heat capacity, $C_{p}$, data of the measured ILs have been evaluated at 298.15 and $323.15 \mathrm{~K}$ by following the method described by Preiss et al. ${ }^{22}$ This method is fully implemented in the COSMOthermX (version C30 1601, COSMOlogic) software within the Ionic Liquids Properties option. ${ }^{34}$ Prior to use, the structure of each involved ion was optimized, with a convergence criterion of $10^{-8}$ hartree in the gas phase, by using density functional theory (DFT) calculations within the Turbomole 7.0 program package ${ }^{35}$ utilizing the B3LYP functional with the def-TZVP basis set, ${ }^{36}$ and combining the Resolution of Identity (RI) approximation. ${ }^{37}$ Each resultant optimized structure was then used as an input for the generation of the COSMO file within the sigma profile of each conformer of each ion using the COSMOconfX 
Table 2. Molar Isobaric Heat Capacities ${ }^{a} C_{p}$ of $\left[\mathrm{C}_{n} \mathrm{C}_{1} \mathrm{im}\right]\left[\mathrm{NTf}_{2}\right]$ Measured within the Temperature Range 293.15-323.15 $\mathrm{K}$ at Atmospheric Pressure

\begin{tabular}{|c|c|c|c|c|c|c|c|}
\hline \multirow[b]{2}{*}{$T / \mathrm{K}$} & \multicolumn{7}{|c|}{$C_{p} / \mathrm{J} \cdot \mathrm{K}^{-1} \cdot \mathrm{mol}^{-1}$} \\
\hline & {$\left[\mathrm{C}_{2} \mathrm{C}_{1} \mathrm{im}\right]\left[\mathrm{NTf}_{2}\right]$} & {$\left[\mathrm{C}_{3} \mathrm{C}_{1} \mathrm{im}\right]\left[\mathrm{NTf}_{2}\right]$} & {$\left[\mathrm{C}_{4} \mathrm{C}_{1} \mathrm{im}\right]\left[\mathrm{NTf}_{2}\right]$} & {$\left[\mathrm{C}_{5} \mathrm{C}_{1} \mathrm{im}\right]\left[\mathrm{NTf}_{2}\right]$} & {$\left[\mathrm{C}_{6} \mathrm{C}_{1} \mathrm{im}\right]\left[\mathrm{NTf}_{2}\right]$} & {$\left[\mathrm{C}_{7} \mathrm{C}_{1} \mathrm{im}\right]\left[\mathrm{NTf}_{2}\right]$} & {$\left[\mathrm{C}_{8} \mathrm{C}_{1} \mathrm{im}\right]\left[\mathrm{NTf}_{2}\right]$} \\
\hline 293.15 & 497.6 & 525.7 & 560.7 & 592.2 & 622.6 & 657.3 & 698.4 \\
\hline 295.65 & 498.9 & 526.9 & 562.4 & 593.8 & 624.3 & 659.1 & 700.2 \\
\hline 298.15 & 500.3 & 528.1 & 564.0 & 595.5 & 625.9 & 660.9 & 702.0 \\
\hline 300.65 & 501.6 & 529.4 & 565.6 & 597.1 & 627.6 & 662.7 & 703.8 \\
\hline 303.15 & 502.9 & 530.7 & 567.2 & 598.7 & 629.3 & 664.4 & 705.7 \\
\hline 305.65 & 504.2 & 532.0 & 568.7 & 600.4 & 631.0 & 666.2 & 707.6 \\
\hline 308.15 & 505.6 & 533.4 & 570.1 & 602.0 & 632.7 & 668.0 & 709.5 \\
\hline 310.65 & 507.0 & 534.7 & 571.5 & 603.6 & 634.4 & 669.8 & 711.5 \\
\hline 313.15 & 508.3 & 536.1 & 572.9 & 605.3 & 636.2 & 671.6 & 713.4 \\
\hline 315.65 & 509.7 & 537.6 & 574.3 & 606.9 & 638.0 & 673.4 & 715.4 \\
\hline 318.15 & 511.2 & 539.0 & 575.5 & 608.6 & 639.8 & 675.2 & 717.5 \\
\hline 320.65 & 512.6 & 540.5 & 576.8 & 610.2 & 641.7 & 677.0 & 719.5 \\
\hline 323.15 & 514.1 & 542.1 & 578.0 & 611.8 & 643.6 & 678.8 & 721.6 \\
\hline
\end{tabular}

Table 3. Molar Isobaric Heat Capacities ${ }^{a} C_{p}$ of $\left[\mathrm{C}_{n} \mathrm{C}_{1} \mathrm{im}\right]_{2}\left[\mathrm{Co}(\mathrm{NCS})_{4}\right]$ and $\left[\mathrm{C}_{n} \mathrm{C}_{1} \mathrm{pyr}\right]\left[\mathrm{NTf}_{2}\right]$ Measured within the Temperature Range 293.15-323.15 K at Atmospheric Pressure

\begin{tabular}{|c|c|c|c|c|}
\hline \multirow[b]{2}{*}{$T / \mathrm{K}$} & \multicolumn{4}{|c|}{$C_{p} / \mathrm{J} \cdot \mathrm{K}^{-1} \cdot \mathrm{mol}^{-1}$} \\
\hline & {$\left[\mathrm{C}_{2} \mathrm{C}_{1} \mathrm{im}\right]_{2}\left[\mathrm{Co}(\mathrm{NCS})_{4}\right]$} & {$\left[\mathrm{C}_{4} \mathrm{C}_{1} \mathrm{im}\right]_{2}\left[\mathrm{Co}(\mathrm{NCS})_{4}\right]$} & {$\left[\mathrm{C}_{3} \mathrm{C}_{1} \mathrm{pyr}\right]\left[\mathrm{NTf}_{2}\right]$} & {$\left[\mathrm{C}_{4} \mathrm{C}_{1} \mathrm{pyr}\right]\left[\mathrm{NTf}_{2}\right]$} \\
\hline 293.15 & 755.0 & 867.1 & 561.3 & 588.8 \\
\hline 295.65 & 756.4 & 868.6 & 563.0 & 590.4 \\
\hline 298.15 & 757.7 & 870.2 & 564.7 & 591.9 \\
\hline 300.65 & 759.1 & 871.8 & 566.3 & 593.4 \\
\hline 303.15 & 760.5 & 873.5 & 567.9 & 595.0 \\
\hline 305.65 & 761.9 & 875.1 & 569.5 & 596.6 \\
\hline 308.15 & 763.4 & 876.9 & 571.0 & 598.2 \\
\hline 310.65 & 764.8 & 878.7 & 572.5 & 599.9 \\
\hline 313.15 & 766.3 & 880.5 & 574.0 & 601.6 \\
\hline 315.65 & 767.8 & 882.5 & 575.5 & 603.3 \\
\hline 318.15 & 769.3 & 884.5 & 576.9 & 605.1 \\
\hline 320.65 & 770.9 & 886.7 & 578.3 & 607.0 \\
\hline 323.15 & 772.5 & 888.9 & 579.7 & 608.9 \\
\hline
\end{tabular}

program (version 3$). .^{38}$ In the case of the $\left[\mathrm{Co}(\mathrm{NCS})_{4}\right]^{2-}$-based ILs, as the COSMOthermX Ionic Liquids Properties option can "only" evaluate the heat capacity (and other properties such as density, viscosity, and conductivity) of ILs containing only singly charged ions, ${ }^{34}$ a metafile approach has been used to generate a "pseudo singly charged anion" containing the COSMO files of the most stable conformation for both the cation (e.g., $\left[\mathrm{C}_{2} \mathrm{C}_{1} \mathrm{im}\right]^{+}$or $\left[\mathrm{C}_{4} \mathrm{C}_{1} \mathrm{im}\right]^{+}$) and the $\left[\mathrm{Co}(\mathrm{NCS})_{4}\right]^{2-}$ anion using the COSMOweight software. ${ }^{34}$ Each generated metafile anion (i.e., $\left\{\left[\mathrm{C}_{2} \mathrm{C}_{1} \mathrm{im}\right]\left[\mathrm{Co}(\mathrm{NCS})_{4}\right]\right\}^{-}$and $\left\{\left[\mathrm{C}_{4} \mathrm{C}_{1} \mathrm{im}\right]\right.$ $\left.\left[\mathrm{Co}(\mathrm{NCS})_{4}\right]\right\}^{-}$) is then treated, within COSMOthermX, as a singly charged anion based on the COSMO file of the selected ions. $^{34}$

\section{RESULTS AND DISCUSSION}

3.1. Isobaric Heat Capacities. The results were recorded with the step $0.01 \mathrm{~K}$ over the temperature range studied. The obtained experimental values of the molar isobaric heat capacities $C_{p}\left(C_{p}=M c_{p}\right.$, where $M$ is molar mass, $c_{p}$ is specific isobaric heat capacity) in the investigated temperature range (each time all recorded experimental points, i.e., ca. 3000 raw experimental data points) were approximated by the polynomials in the form

$$
C_{p}=\sum_{i=0}^{3} A_{i}((T-293.15) / 100)^{i}
$$

where $A_{i}$ are fitting coefficients and $T$ is temperature. The obtained (using unweighted least-squares method) $A_{i}$ coefficients and the standard deviations from the regression lines $\delta$ are reported in Table S1 of the Supporting Information (SI), whereas Tables 2 and 3 list the values of $C_{p}$ in the temperature range from 293.15 to $323.15 \mathrm{~K}$ with a $2.5 \mathrm{~K}$ step.

In the following sections we discuss separately the results for each homologous series together with the available (for the investigated temperature range) literature data sets; all uncertainties of the literature data given in this work are the original values reported by authors. If such numerical data have been available, the agreement between our and literature data is demonstrated in deviation plots. In some cases, however, only very limited isothermal reports regarding isobaric heat capacity can be found. It should be noted that a compilation of the oldest data on $C_{p}$ (up to 2010) for ILs can be found in papers of Zábranský et al. ${ }^{29}$ and Paulechka. ${ }^{39}$ 
3.1.1. 1-Alkyl-3-methylimidazolium Bis(trifluoromethylsulfonyl)imides. In the case of $\left[\mathrm{C}_{n} \mathrm{C}_{1} \mathrm{im}\right]$ $\left[\mathrm{NTf}_{2}\right]$, the number of published data on the molar isobaric heat capacity varies strongly with the number of carbon atoms on the alkyl chain length of the cation; limited data sets are only available especially when $n$ is an odd number. For example, in the cases of $\left[\mathrm{C}_{5} \mathrm{C}_{1} \mathrm{im}\right]\left[\mathrm{NTf}_{2}\right]$ and $\left[\mathrm{C}_{7} \mathrm{C}_{1} \mathrm{im}\right]\left[\mathrm{NTf}_{2}\right]$, only onepoint data sets exist. ${ }^{18}$ On the other hand, in the case when $n$ is an even number, for example in the case of $\left[\mathrm{C}_{4} \mathrm{C}_{1} \mathrm{im}\right]\left[\mathrm{NTf}_{2}\right]$, over a dozen data sets exist. ${ }^{9,13,18,40-50}$ Below we critically analyzed each one of the imidazolium-based ILs for the homologous series of $\left[\mathrm{C}_{n} \mathrm{C}_{1} \mathrm{im}\right]\left[\mathrm{NTf}_{2}\right]$, where $n=2-8$.

$\left[C_{2} C_{1}\right.$ im $]\left[N T f_{2}\right]$. Apart from the results of Gómez et al. ${ }^{9}$ (Figure 1 and Table S2), the maximal difference between the

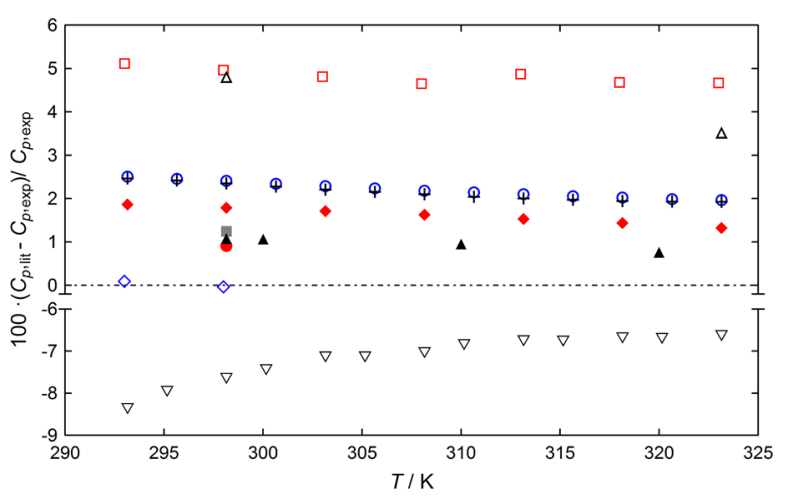

Figure 1. Deviations between $C_{p, \exp }$ values obtained in this work (eq 1) and reported literature values $C_{p, \text { lit }}$ shown as $\left(C_{p, \text { lit }}-C_{p, \exp }\right) / C_{p, \exp }$ in the temperature range from 293.15 to $323.15 \mathrm{~K}$ for $\left[\mathrm{C}_{2} \mathrm{C}_{1}\right.$ im] $]\left[\mathrm{NTf}_{2}\right]$ : $\nabla$, ref $9 ; \bigcirc$, ref $46 ; \bullet$, ref $18 ; \square$, ref $13 ; \triangle$, ref $40 ; \diamond$, ref $54 ; \diamond$, ref 51; $\boldsymbol{\Delta}$, ref 52; $\mathbf{\square}$, ref 53; and + , ref 55 .

$C_{p}$ values is about $5 \%$. Thus, the consistency is relatively good (AARD close to $3.3 \%$ ). However, when we ignore the three data sets, i.e., the above-mentioned data of Gómez et al. ${ }^{9}$ as well as data of Fredlake et al. ${ }^{40}$ and Ge et al. ${ }^{13}$ which show the greatest deviations, the rest of the data show deviations below $2.5 \%$. Note that all three mentioned data sets were obtained by DSC with speed scanning rates (e.g., $\left.20 \mathrm{~K} \cdot \mathrm{min}^{-1}\right)^{9,13}$ and by use of very small samples $(\leq 0.1 \mathrm{~mL})$ enclosed in sample pans. Generally, the best accordance with our data show the $C_{p}$ values reported by Yamamuro et al. $^{51}$ and obtained from drop calorimetry (DC) by Rocha et al. ${ }^{18}$ Also good accordance shows data reported by Paulechka et al. ${ }^{52}$ and Shimizu et al. ${ }^{53}$ obtained from adiabatic calorimetry (AC). Fairly good accordance shows also data reported by Waliszewski et al. ${ }^{54}$ from a Tian-Calvet DSC (TC DSC) calorimeter. The slight difference between the new values reported in this work and data in our previous works ${ }^{46,55}$ can be connected to the contamination of the sample by varying amounts of water.

$\left[C_{3} C_{1} i m\right]\left[N T f_{2}\right]$. Apart from the polythermal data set (293$333 \mathrm{~K})$ reported by Gómez et al., ${ }^{9}$ only two additional isothermal values at $298.15 \mathrm{~K}$ are reported in the available literature. $^{18,19}$ At $298.15 \mathrm{~K}$ the maximal difference between the values $489 \pm 25,534.9 \pm 0.5$, and $492 \pm 1 \mathrm{~J} \cdot \mathrm{mol}^{-1} \cdot \mathrm{K}^{-1}$ reported by Gómez et al., ${ }^{9}$ Rocha et al., ${ }^{18}$ and Gómez et al., ${ }^{19}$ respectively, is equal to ca. $9 \%$. At the same time the value $528.2 \pm 5.3 \mathrm{~J} \cdot \mathrm{mol}^{-1} \cdot \mathrm{K}^{-1}$ obtained in this work is in good agreement with the value obtained from $\mathrm{DC}$ by Rocha et al. ${ }^{18}$ Large deviations in the case of Gómez et al.'s, ${ }^{9}$ data are most probably connected to the instrumentation (DSC calibration, measurement procedure, e.g., scan rate $20 \mathrm{~K} \cdot \mathrm{min}^{-1}$, 9 and small sample $\leq 0.1 \mathrm{~mL}$ ) because other properties such as density $\rho$ and speed of sound $c$ reported in ref 19 are in good agreement with those reported by us. ${ }^{23}$ The average absolute relative deviation (AARD)

$$
\text { AARD }=100 N^{-1} \sum_{i=1}^{N} \mathrm{I}\left(y_{\text {ref } 19}-y_{\text {ref } 23}\right) / y_{\text {ref } 23} \mathrm{I}
$$

where $N$ is the number of data and $y$ denotes $\rho$ or $c$, respectively, was calculated to be close to 0.042 and $0.13 \%$ for $\rho$ and $c$, respectively.

$\left[C_{4} C_{1}\right.$ im $]\left[N T f_{2}\right]$. Apart from data of Holbrey et al. $^{48}$ (modulated differential scanning calorimetry (MDSC) was used) and Zhang and Reddy ${ }^{49}$ that are not taken into account because these data show extreme deviations, e.g., at $298.15 \mathrm{~K}$ of -23 and $-19 \%$, respectively, the difference between remaining values (Figure 2 and Table S3) reaches here $11.7 \%$ at $298.15 \mathrm{~K}$

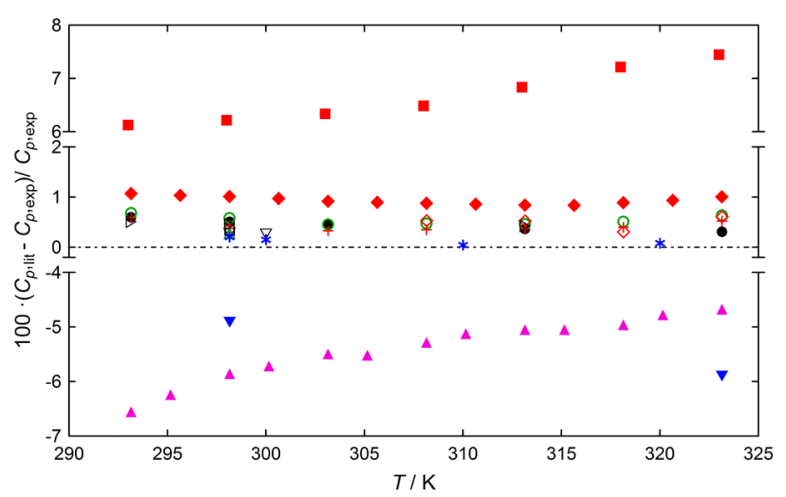

Figure 2. Deviations between $C_{p, \exp }$ values obtained in this work (eq 1) and reported literature values $C_{p, \text { lit }}$ shown as $\left(C_{p, \text { lit }}-C_{p \text {,exp }}\right) / C_{p \text {,exp }}$ in the temperature range from 293.15 to $323.15 \mathrm{~K}$ for $\left[\mathrm{C}_{4} \mathrm{C}_{1} \mathrm{im}\right]\left[\mathrm{NTf}_{2}\right]$ : $\boldsymbol{\nabla}, \operatorname{ref} 40 ; \mathbf{\square}, \operatorname{ref} 13 ; \boldsymbol{\bullet}, \operatorname{ref} 41 ; \bigcirc, \operatorname{ref} 42 ;+, \operatorname{ref} 42 ; *, \operatorname{ref} 44 ; \triangle$, ref 43; $\nabla$, ref $45 ; \diamond$, ref 46 ; $\diamond$, ref 47 ; $\boldsymbol{\Delta}$, ref 9 ; $\square$, ref 18 ; and $\triangleright$, ref 50 .

(generally, an AARD close to $2.2 \%$ was found). Thus, the agreement is still rather poor; however, three data sets ${ }^{9,13,40}$ are mainly responsible for the situation. All three above data sets were obtained using DSC and very low samples $(\leq 0.1$ $\mathrm{mL}){ }^{9,13,40}$ However, when these values are also omitted, the remaining sets of data agree within $1 \%$. Thus, their consistency can be considered as excellent.

$\left[\mathrm{C}_{5} \mathrm{C}_{7}\right.$ im] $\left[N T f_{2}\right]$. In this case, apart from one isothermal data of Rocha et al. ${ }^{18}$ at $298.15 \mathrm{~K}\left(595.6 \pm 0.5 \mathrm{~J} \cdot \mathrm{mol}^{-1} \cdot \mathrm{K}^{-1}\right)$ obtained from DC, no other literature $C_{p}$ data are available. An excellent agreement between the above single literature value and the value determined in this work of $595.6 \pm 6 \mathrm{~J} \cdot \mathrm{mol}^{-1} \cdot \mathrm{K}^{-1}$ is observed.

$\left[C_{6} C_{7} i m\right]\left[N T f_{2}\right]$. This IL is recommended by the IUPAC Commission as a reference substance, ${ }^{56}$ and the literature data are here relatively numerous. ${ }^{9,12,13,18,57-62}$ Here, an AARD close to $3.5 \%$ was found. The obtained $C_{p}$ value in this study at $298.15 \mathrm{~K}\left(625.8 \pm 6.3 \mathrm{~J} \cdot \mathrm{mol}^{-1} \cdot \mathrm{K}^{-1}\right)$ is slightly smaller than the recommended value of $631.6 \pm 1.3 \mathrm{~J} \cdot \mathrm{mol}^{-1} \cdot \mathrm{K}^{-1}$, but taking into account the estimated uncertainties, the agreement is very good. This result can be treated as an additional confirmation of the reliability of all the results presented in this work. Note also that the extrapolated $C_{p}$ value at $298.15 \mathrm{~K}(626 \pm 2 \mathrm{~J}$. $\mathrm{mol}^{-1} \cdot \mathrm{K}^{-1}$ ) obtained by Bochmann and Hefter ${ }^{60}$ in their study (TC DSC) at $10 \mathrm{MPa}$ in the temperature range $323-573 \mathrm{~K}$ 
also shows very good agreement with the value obtained in this work. Thus, the $C_{p}$ value determined at $10 \mathrm{MPa}$ by the above authors is also valid at $0.1 \mathrm{MPa}$ as was already postulated in the original work because of practical independence on pressure in this range. Apart from data of Crosthwaite et al. ${ }^{12}$ and $\mathrm{Ge}$ et al. $^{13}$ (in both cases, DSC with speed scan rates of 10 or $20 \mathrm{~K}$. $\mathrm{min}^{-1}$ and very low samples of $\leq 0.1 \mathrm{~mL}$ were used) with the relative deviations up to -7 and $8 \%$, respectively, the rest of data show deviations in the range $\pm 5 \%$ (Figure 3 and Table

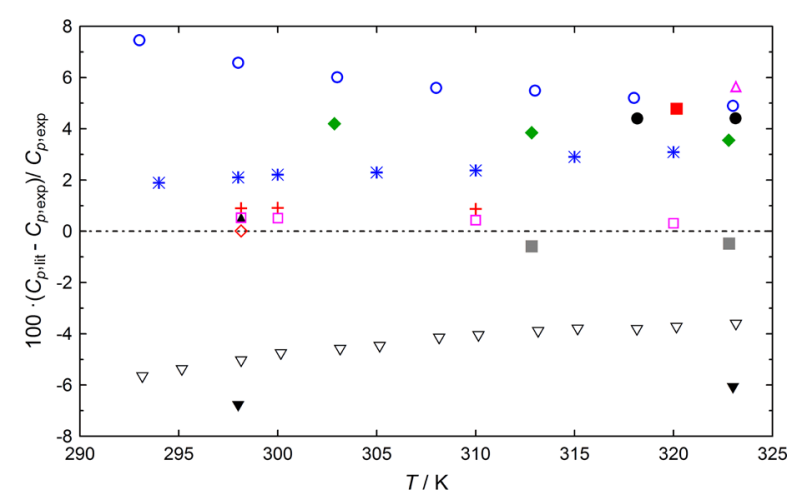

Figure 3. Deviations between $C_{p, \exp }$ values obtained in this work (eq 1) and reported literature values $C_{p, \text { lit }}$ shown as $\left(C_{p, \text { lit }}-C_{p, \exp }\right) / C_{p, \exp }$ in the temperature range from 293.15 to $323.15 \mathrm{~K}$ for $\left[\mathrm{C}_{6} \mathrm{C}_{1} \mathrm{im}\right]\left[\mathrm{NTf}_{2}\right]$ : $\nabla$, ref $9 ; \nabla$, ref $12 ; \bigcirc$, ref $13 ;+$, ref $57 ; \square$, ref $58 ; *$, ref $59 ; \diamond$, ref 60 ; $\diamond$, ref 61; $\mathbf{\square}$ (gray), ref 61; $\bullet$, ref 62; $\mathbf{\square}$ (red), ref 62; $\triangle$, ref 62; and $\boldsymbol{\Delta}$, ref 18 .

S4). However, similarly as in the cases of $\left[\mathrm{C}_{n} \mathrm{C}_{1} \mathrm{im}\right]\left[\mathrm{NTf}_{2}\right]$ with $n=2,3,4$, the data of Gómez et al. ${ }^{9}$ show here also significant relative deviations of about $-5 \%$. In other words, these data are always lower in relation to data obtained in this work.

$\left[C_{7} C_{1} i m\right]\left[N T f_{2}\right]$. Here, similar to the case of $\left[\mathrm{C}_{5} \mathrm{C}_{1} \mathrm{im}\right]\left[\mathrm{NTf}_{2}\right]$ only one other one-point data set exists. The agreement at 298.15 $\mathrm{K}$ of the value obtained in this work $(661.0 \pm 6.6 \mathrm{~J}$. $\left.\mathrm{mol}^{-1} \cdot \mathrm{K}^{-1}\right)$ and the literature value of Rocha et al. ${ }^{18}(659.2 \pm$ $\left.0.7 \mathrm{~J} \cdot \mathrm{mol}^{-1} \cdot \mathrm{K}^{-1}\right)$ is here also excellent.

$\left[C_{8} C_{1} i m\right]\left[N T f_{2}\right]$. The discrepancies in the reported values (Figure 4 and Table S5) are similar to those for $\left[\mathrm{C}_{6} \mathrm{C}_{1} \mathrm{im}\right]$ [NTf $\mathrm{NT}_{2}$, and AARD close to $2.8 \%$ was found. At $298.15 \mathrm{~K}$, the difference between extreme values reaches here $12 \%$. Rejecting

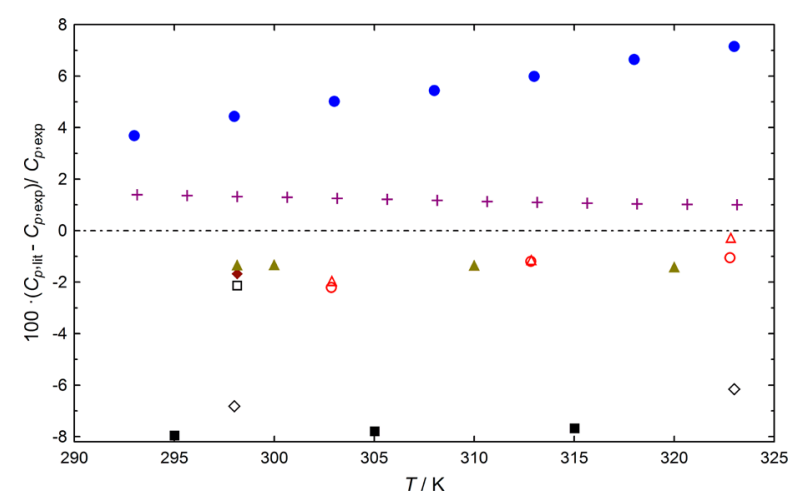

Figure 4. Deviations between $C_{p, \exp }$ values obtained in this work (eq 1) and reported literature values $C_{p, \text { lit }}$ shown as $\left(C_{p, \text { lit }}-C_{p, \exp }\right) / C_{p, \exp }$ in the temperature range from 293.15 to $323.15 \mathrm{~K}$ for $\left[\mathrm{C}_{8} \mathrm{C}_{1} \mathrm{im}\right]\left[\mathrm{NTf}_{2}\right]$ : $\diamond$, ref $12 ; \boldsymbol{\bullet}$, ref $13 ; \mathbf{\square}$, ref $14 ; \diamond$, ref $18 ;+$, ref $46 ; \boldsymbol{\Delta}$, ref $52 ; \square$, ref $60 ; \triangle$, ref 61 ; and $\bigcirc$, ref 61 . the extreme values (obtained by DSC and very low samples of $\leq 0.1 \mathrm{~mL}$ ) from Ge et al., ${ }^{13}$ Crosthwaite et al., ${ }^{12}$ and Chatel et al., ${ }^{14}$ the rest of the data agree very well within the range of $\pm 2 \%$. The analysis also shows that the values obtained in this work are a bit higher than most of the literature data.

Summing up, for the investigated homologues of the $\left[\mathrm{C}_{n} \mathrm{C}_{1} \mathrm{im}\right]\left[\mathrm{NTf}_{2}\right]$ series in comparison with the literature data, the best agreements were observed in the cases of $\left[\mathrm{C}_{5} \mathrm{C}_{1} \mathrm{im}\right]$ $\left[\mathrm{NTf}_{2}\right]$ and $\left[\mathrm{C}_{7} \mathrm{C}_{1} \mathrm{im}\right]\left[\mathrm{NTf}_{2}\right]$ which comprised the least number of the literature data. For even homologues where the data are more numerous, the deviations are generally fairly different. However, rejecting some large outliers in the cases of $\left[\mathrm{C}_{2} \mathrm{C}_{1} \mathrm{im}\right]\left[\mathrm{NTf}_{2}\right], \quad\left[\mathrm{C}_{4} \mathrm{C}_{1} \mathrm{im}\right]\left[\mathrm{NTf}_{2}\right], \quad\left[\mathrm{C}_{6} \mathrm{C}_{1} \mathrm{im}\right]\left[\mathrm{NTf}_{2}\right]$, and $\left[\mathrm{C}_{8} \mathrm{C}_{1} \mathrm{im}\right]\left[\mathrm{NTf}_{2}\right]$, the deviations fall to below $\pm 3 \%$. With the exception of $\left[\mathrm{C}_{8} \mathrm{C}_{1} \mathrm{im}\right]\left[\mathrm{NTf}_{2}\right]$, our data are generally rather slightly lower than most of the literature data. Although the available literature data were obtained by various methods and instruments, it is noticeable that the highest deviations are mostly connected to DSC calorimetry using speed scanning rates (e.g., $10 \mathrm{~K} \cdot \mathrm{min}^{-1}$ and more) and small samples $(\leq 0.1$ $\mathrm{mL})^{9,12-14,40,48,49}$ This is not surprising as this has been previously reported $^{60,61}$ and can be treated as rather a general rule. In turn, TC DSC calorimetry with a slow (and very slow) scan rate $\left(<1-2 \mathrm{~K} \cdot \mathrm{min}^{-1}\right)$ and relatively large samples $(1-10$ $\mathrm{mL}$ ) give generally much more reliable results that are consistent with AC and DC results. Other, significant source of errors in the $C_{p}$ measurements can be impurities. However, unfortunately, inspection of original works does not give a clear and uniform picture in this matter because some papers lack any information about purity. In older papers, however, the sample purity was rather generally worse. The effect of 0.01 mass fraction of possible impurities on the specific heat capacity $c_{p}$ has been analyzed in detail by Paulechka et al. ${ }^{63}$ for the IL $\left[\mathrm{C}_{4} \mathrm{C}_{1} \mathrm{im}\right]\left[\mathrm{BF}_{4}\right]$. According to the mentioned authors, the level of impurities (such as residual solvents and reagents carried over from the synthesis) typical for the best available samples is not critical (had little impact on the $c_{p}$ ) in all cases with exception of water; i.e., only water is the impurity which shifted the $c_{p}$ of the sample significantly. Hence, the possible absorption of water during the experiment is especially important in the case of small samples.

3.1.2. 1-Alkyl-1-methylpyrrolidinium Bis(trifluoromethylsulfonyl)imides. Experimental heat capacity data for these ILs are rather scarce; however, the difference in number of data sets for 1-propyl- (odd carbon number) and 1butyl- (even carbon number) carbon chains in the cation is also visible here (Figure 5 and Table S6). Two sets of previously published experimental data for $\left[\mathrm{C}_{3} \mathrm{C}_{1}\right.$ pyr $]\left[\mathrm{NTf}_{2}\right]$ are available, ${ }^{54,64}$ and five published results are available for $\left[\mathrm{C}_{4} \mathrm{C}_{1}\right.$ pyr $]$ $\left[\mathrm{NTf}_{2}\right]{ }^{13,14,45,65,63}$ Unfortunately, as mentioned in the Introduction, the experimental data sets for $\left[\mathrm{C}_{4} \mathrm{C}_{1} \mathrm{pyr}\right]\left[\mathrm{NTf}_{2}\right]$ have a high degree of scatter, nearly $20 \%$. Excluding the extreme values of Ge et al. ${ }^{13}$ and Chatel et al., ${ }^{14}$ the rest of data $^{45,65,63}$ show a satisfactory agreement. Strictly speaking, the data of Paulechka et al. ${ }^{63}$ and Shimizu et al. ${ }^{45}$ show very good agreement (deviations below -1\%), whereas the data of Rao et al. ${ }^{65}$ show a satisfactory agreement of ca. $3 \%$. In turn, in the case of $\left[\mathrm{C}_{3} \mathrm{C}_{1}\right.$ pyr $]\left[\mathrm{NTf}_{2}\right]$ the reported data differs generally by ca. $5 \%$; here, our data show much better consistency with the older data of Waliszewski et al. ${ }^{54}$ than with those reported recently by González and González. ${ }^{64}$

The conclusions are similar to those in the case of the $\left[\mathrm{C}_{n} \mathrm{C}_{1} \mathrm{im}\right]\left[\mathrm{NTf}_{2}\right]$ ILs. The most consistent and reliable results 


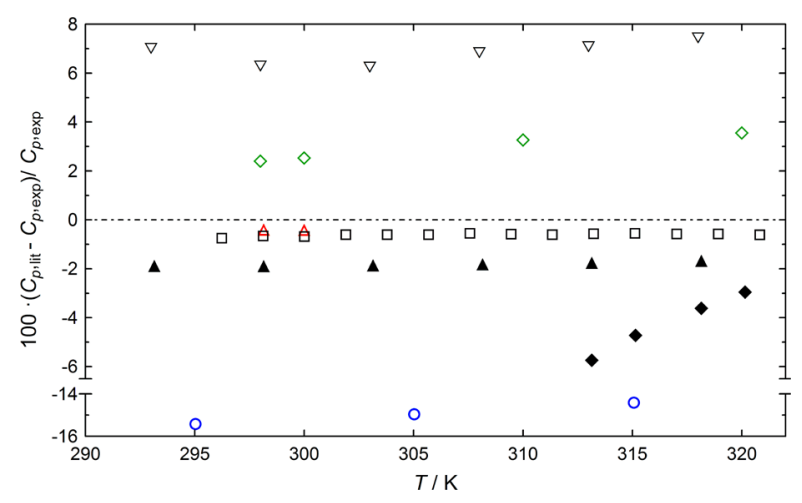

Figure 5. Deviations between experimental values $C_{p, \exp }$ obtained in this work (eq 1$)$ and literature values $C_{p, \text { lit }}$ shown as $\left(C_{p, \text { lit }}-C_{p, \text { exp }}\right) /$ $C_{p, \exp }$ in the temperature range from 293.15 to $323.15 \mathrm{~K}$ for $\left[\mathrm{C}_{3} \mathrm{C}_{1}\right.$ pyr $]\left[\mathrm{NTf}_{2}\right]$ (empty symbols) and $\left[\mathrm{C}_{4} \mathrm{C}_{1}\right.$ pyr $]\left[\mathrm{NTf}_{2}\right]$ (filled symbols): $\nabla$, ref $13 ; 0$, ref $14 ; \triangle$, ref $45 ; \diamond$, ref $65 ; \square$, ref $63 ; \boldsymbol{\Delta}$, ref 54; and $\diamond$, ref 64 .

are obtained mainly from AC and TC DSC with samples and scan rates similar to those in this work.

3.1.3. Bis(1-alkyl-3-methylimidazolium) Tetrathiocyanatocobaltates. Because of a lack of literature values in the cases of $\left[\mathrm{C}_{2} \mathrm{C}_{1} \mathrm{im}\right]_{2}\left[\mathrm{Co}(\mathrm{NCS})_{4}\right]$ and $\left[\mathrm{C}_{4} \mathrm{C}_{1} \mathrm{im}\right]_{2}\left[\mathrm{Co}(\mathrm{NCS})_{4}\right]$, the values reported in this work are recommended. As in the abovediscussed series, heat capacity increases with the increase of the alkyl side chain length in the imidazolium ring of the cation; i.e., the molar (specific as well) isobaric heat capacity of $\left[\mathrm{C}_{4} \mathrm{C}_{1} \mathrm{im}\right]_{2}\left[\mathrm{Co}(\mathrm{NCS})_{4}\right]$ is higher than that of $\left[\mathrm{C}_{2} \mathrm{C}_{1} \mathrm{im}\right]_{2}[\mathrm{Co}-$ $\left.(\mathrm{NCS})_{4}\right]$.

The specific isobaric heat capacities are rather moderate or even can be classified as low because at $298.15 \mathrm{~K}$ the values are equal $\left(1.475\right.$ and $1.527 \mathrm{~J} \cdot \mathrm{g}^{-1} \cdot \mathrm{K}^{-1}$ for $\left[\mathrm{C}_{2} \mathrm{C}_{1} \mathrm{im}\right]_{2}\left[\mathrm{Co}(\mathrm{NCS})_{4}\right]$ and $\left[\mathrm{C}_{4} \mathrm{C}_{1} \mathrm{im}\right]_{2}\left[\mathrm{Co}(\mathrm{NCS})_{4}\right]$, respectively). Although the above values are the highest of all the ILs determined in this work, these values are evidently smaller than in the cases of the recently reported salicylate-based-protic ILs $\left(1.87-1.98 \mathrm{~J} \cdot \mathrm{g}^{-1}\right.$. $\left.\mathrm{K}^{-1}\right)^{11}$ and other known ILs with high specific heat capacities. ${ }^{63}$

3.1.4. Effect of Elongation of Alkyl Carbon Chain Length in the Cation on Heat Capacity. The $C_{p}$ values for $\left[\mathrm{C}_{n} \mathrm{C}_{1} \mathrm{im}\right]\left[\mathrm{NTf}_{2}\right]$ reported in this work increase regularly with the increase of the alkyl chain length in the imidazolium ring of the cation and no odd and even effect is observed; i.e., this indicates that each $\mathrm{CH}_{2}$ group equally contributes to the $C_{p}$ values. The increase of $C_{p}$ with the increasing elongation of the alkyl chain (the structure complexity of the cation) has also been reported previously ${ }^{18,53,63}$ and results from the increase of rotational and vibrational degrees of freedom. The effect of increasing the alkyl chain length of the cation on the $C_{p}$ values reported in this work is equal to $33.3 \pm 0.7 \mathrm{~J} \cdot \mathrm{K}^{-1} \cdot \mathrm{mol}^{-1}$ per $\mathrm{CH}_{2}$ group at $298.15 \mathrm{~K}$, and this value is in good agreement with the value obtained from the data of Rocha et al. ${ }^{18}(31.5+$ $\left.0.2 \mathrm{~J} \cdot \mathrm{K}^{-1} \cdot \mathrm{mol}^{-1}\right)$ and of Paulechka et al. ${ }^{63}\left(31.8 \pm 0.4 \mathrm{~J} \cdot \mathrm{K}^{-1}\right.$. $\left.\mathrm{mol}^{-1}\right)$. The obtained value for the $\left[\mathrm{C}_{n} \mathrm{C}_{1} \mathrm{im}\right]\left[\mathrm{NTf}_{2}\right]$ series also agrees very well with the value for quite structurally different ILs, i.e., salicylate-based-protic ILs $\left(33.0 \mathrm{~J} \cdot \mathrm{K}^{-1} \cdot \mathrm{mol}^{-1}\right){ }^{11}$ At $323.15 \mathrm{~K}$, the effect of increasing the alkyl chain length of the cation on the $C_{p}$ per $\mathrm{CH}_{2}$ group is equal to $34.3 \pm 0.7 \mathrm{~J} \cdot \mathrm{K}^{-1}$. $\mathrm{mol}^{-1}$ for $\left[\mathrm{C}_{n} \mathrm{C}_{1} \mathrm{im}\right]\left[\mathrm{NTf}_{2}\right]$ studied in this work and $33.8 \mathrm{~J} \cdot \mathrm{K}^{-1}$. $\mathrm{mol}^{-1}$ for salicylate-based-protic ILs, ${ }^{11}$ respectively. Thus, in the studied temperature range this effect is very similar.
In the case of $\left[\mathrm{C}_{n} \mathrm{C}_{1} \mathrm{pyr}\right]\left[\mathrm{NTf}_{2}\right]$, the effect of increasing the alkyl side chain length of the cation on the $C_{p}$ (calculated from selected reliable data only, from refs 45 and 54 and this work) is equal to $31.4 \pm 5.5 \mathrm{~J} \cdot \mathrm{K}^{-1} \cdot \mathrm{mol}^{-1}$ per $\mathrm{CH}_{2}$ group at $298.15 \mathrm{~K}$. In turn, the effect of increasing the alkyl side chain length of the cation on the $C_{p}$ in $\left[\mathrm{C}_{n} \mathrm{C}_{1} \mathrm{im}\right]_{2}\left[\mathrm{Co}(\mathrm{NCS})_{4}\right]$ is equal to $28.1 \mathrm{~J}$. $\mathrm{K}^{-1} \cdot \mathrm{mol}^{-1}$ per $\mathrm{CH}_{2}$ group at $298.15 \mathrm{~K}$. This effect, although similar, is however smaller than those reported for other IL series. It should be noted, however, that in both cases these values are calculated based on only two members of each series.

Figure 6a shows the most reliable $C_{p}$ values for all analyzed homologues of the $\left[\mathrm{C}_{n} \mathrm{C}_{1} \mathrm{im}\right]\left[\mathrm{NTf}_{2}\right]$ series (selected as
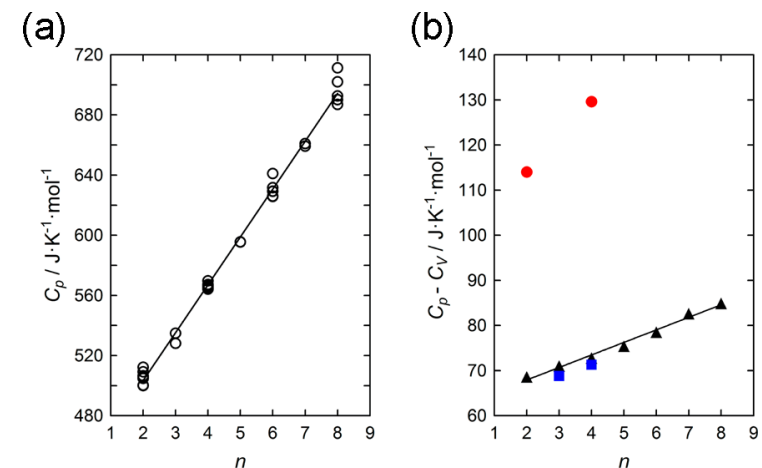

Figure 6. (a) Molar isobaric heat capacities $C_{p}$ as a function of number of carbon atoms $n$ in the alkyl side chain of the imidazolium ring of the cation for $\left[\mathrm{C}_{n} \mathrm{C}_{1} \mathrm{im}\right]\left[\mathrm{NTf}_{2}\right]$ at $298.15 \mathrm{~K}$; data from refs $18,42-46$, $51-54,57,58$, and 60 and from this work. (b) $C_{p}-C_{V}$ as a function of the number of carbon atoms $n$ in the alkyl side chain of the cation for $\boldsymbol{\Delta}, \quad\left[\mathrm{C}_{n} \mathrm{C}_{1} \mathrm{im}\right]\left[\mathrm{NTf}_{2}\right] ; \boldsymbol{\bullet}, \quad\left[\mathrm{C}_{n} \mathrm{C}_{1} \mathrm{im}\right]_{2}\left[\mathrm{Co}(\mathrm{NCS})_{4}\right]$; and $\left[\mathrm{C}_{n} \mathrm{C}_{1}\right.$ pyr $]\left[\mathrm{NTf}_{2}\right]$, at $298.15 \mathrm{~K}$.

described above) as a function of the number of carbon atoms $n$ in the alkyl side chain of the imidazolium ring of the cation at $298.15 \mathrm{~K}$. The estimated (unweighted least squares) slope of the linear dependence of $C_{p}$ against $n$ is equal to $31.8 \pm$ $0.4 \mathrm{~J} \cdot \mathrm{K}^{-1} \cdot \mathrm{mol}^{-1}$. This result is very similar to those obtained for other series of 1-alkyl-3-methylimidazolium ILs because, apart from the small reliable result of Holbrey et $\mathrm{al}^{48}$ for the hexafluorophosphate anion $\left(41 \mathrm{~J} \cdot \mathrm{K}^{-1} \cdot \mathrm{mol}^{-1}\right)$, the slope is equal to $30.6 \pm 1.7 \mathrm{~J} \cdot \mathrm{K}^{-1} \cdot \mathrm{mol}^{-1}$ for bromide anion ${ }^{63}$ and $31.7 \pm 1.2 \mathrm{~J}$. $\mathrm{K}^{-1} \cdot \mathrm{mol}^{-1}$ for tetrafluoroborate anion. ${ }^{63}$ Thus, the slope of $C_{p}$ against the alkyl chain length is very similar in the above series within experimental error; i.e., each $\mathrm{CH}_{2}$ group equally contributes to $C_{p}$ in each series of 1-alkyl-3-methylimidazolium ILs and the mean value is equal to $31.4 \mathrm{~J} \cdot \mathrm{K}^{-1} \cdot \mathrm{mol}^{-1}$. Thus, summing up, the effect is generally very similar for different IL series. Moreover, as was already previously reported, the contribution of $\mathrm{CH}_{2}$ to $\mathrm{C}_{p}$ can be generalized. ${ }^{53}$ This effect can be generalized because comparison of $\left[\mathrm{C}_{n} \mathrm{C}_{1} \mathrm{im}\right]\left[\mathrm{NTf}_{2}\right]$ series with the alkyl chain length dependence of $C_{p}$ for molecular liquids ( $n$-alkanes, 1-alkanols, and 1-chloroalkanes) showed that the slope against the chain length is nearly equal in all these substances. ${ }^{53}$ Thus, according to Shimizu et al., ${ }^{53}$ "the thermal agitation of the alkyl chain of $\left[\mathrm{C}_{n} \mathrm{C}_{1} \mathrm{im}\right]\left[\mathrm{NTf}_{2}\right]$ in the liquid phase is almost identical to those of typical molecular liquids in spite of the different interactions working between constituent particles".

3.2. Isochoric Heat Capacities. As mentioned in the Introduction, contrary to $C_{p}$ measurements, direct calorimetric measurements of $C_{V}$ are difficult and rarely conducted procedures. Hence, a convenient and well-established method 
Table 4. Densities ${ }^{a}$ of $\left[\mathrm{C}_{n} \mathrm{C}_{1} \mathrm{im}\right]_{2}\left[\mathrm{Co}(\mathrm{NCS})_{4}\right]$ and $\left[\mathrm{C}_{n} \mathrm{C}_{1} \mathrm{pyr}\right]\left[\mathrm{NTf}_{2}\right]$ Measured within the Temperature Range 288.15-363.15 $\mathrm{K}$ at Atmospheric Pressure

\begin{tabular}{|c|c|c|c|c|}
\hline \multirow[b]{2}{*}{$T / \mathrm{K}$} & \multicolumn{4}{|c|}{$\rho / \mathrm{kg} \cdot \mathrm{m}^{-3}$} \\
\hline & {$\left[\mathrm{C}_{2} \mathrm{C}_{1} \mathrm{im}\right]_{2}\left[\mathrm{Co}(\mathrm{NCS})_{4}\right]$} & {$\left[\mathrm{C}_{4} \mathrm{C}_{1} \mathrm{im}\right]_{2}\left[\mathrm{Co}(\mathrm{NCS})_{4}\right]$} & {$\left[\mathrm{C}_{3} \mathrm{C}_{1}\right.$ pyr $]\left[\mathrm{NTf}_{2}\right]$} & {$\left[\mathrm{C}_{4} \mathrm{C}_{1}\right.$ pyr $]\left[\mathrm{NTf}_{2}\right]$} \\
\hline 288.15 & 1292.83 & 1226.31 & 1437.10 & 1403.35 \\
\hline 293.15 & $1289.03^{b}$ & $1222.72^{b}$ & 1432.59 & 1398.93 \\
\hline 298.15 & $1285.37^{b}$ & $1219.12^{b}$ & 1428.07 & 1394.53 \\
\hline 303.15 & 1281.74 & 1215.53 & 1423.57 & 1390.13 \\
\hline 308.15 & 1278.10 & 1212.06 & 1419.07 & 1385.72 \\
\hline 313.15 & 1274.48 & 1208.62 & 1414.60 & 1381.34 \\
\hline 318.15 & 1270.85 & 1205.16 & 1410.13 & 1376.97 \\
\hline 323.15 & 1267.25 & 1201.72 & 1405.68 & 1372.61 \\
\hline 328.15 & 1263.67 & 1198.30 & 1401.25 & 1368.26 \\
\hline 333.15 & 1260.10 & 1194.88 & 1396.83 & 1363.93 \\
\hline 338.15 & 1256.54 & 1191.48 & 1392.43 & 1359.62 \\
\hline 343.14 & 1253.00 & 1188.10 & 1388.05 & 1355.31 \\
\hline 348.15 & 1249.48 & 1184.74 & 1383.68 & 1351.02 \\
\hline 353.15 & 1245.97 & 1181.38 & 1379.33 & 1346.74 \\
\hline 358.15 & 1242.48 & 1178.05 & 1374.99 & 1342.47 \\
\hline 363.15 & 1239.00 & 1174.72 & 1370.66 & 1338.22 \\
\hline
\end{tabular}

for the $C_{V}$ determination is an indirect route based on the speed of sound values (acoustic method). $C_{V}$ can be obtained from the relation

$$
C_{V}=C_{p}-\alpha_{p}{ }^{2} V T \kappa_{T}^{-1}
$$

where $\alpha_{p}\left(\alpha_{p}=-\rho^{-1}(\partial \rho / \partial T)_{p}\right)$ is the isobaric thermal expansion coefficient and $\kappa_{T}$ is the isothermal compressibility coefficient that can be calculated as follows:

$$
\kappa_{T}=\rho^{-1} c^{-2}+\alpha_{p}^{2} V T C_{p}^{-1}
$$

where $c$ is the speed of sound, $V$ denotes the molar volume, and the product $\rho^{-1} \cdot c^{-2}$ is the isentropic compressibility coefficient $\kappa_{S}$.

The data required for these calculations are taken from our previous works ${ }^{23,46}$ or are determined in this work. For $\left[\mathrm{C}_{n} \mathrm{C}_{1} \mathrm{im}\right]_{2}\left[\mathrm{Co}(\mathrm{NCS})_{4}\right]$ and $\left[\mathrm{C}_{n} \mathrm{C}_{1}\right.$ pyr $]\left[\mathrm{NTf}_{2}\right]$, the experimental $\rho$ and $c$ values measured in this work are summarized in Table 4 and Table S7, respectively. The measured $\rho$ and $c$ values for $\left[\mathrm{C}_{7} \mathrm{C}_{1} \mathrm{im}\right]\left[\mathrm{NTf}_{2}\right]$ are listed in Table 5 . The

Table 5. Densities ${ }^{a} \rho$ and Speeds of Sound ${ }^{b} c$ of $\left[\mathrm{C}_{7} \mathrm{C}_{1} \mathrm{im}\right]\left[\mathrm{NTf}_{2}\right]$ Measured within the Temperature Range 293.15-323.15 K at Atmospheric Pressure

\begin{tabular}{ccc}
$T / \mathrm{K}$ & $\rho / \mathrm{kg} \cdot \mathrm{m}^{-3}$ & $c / \mathrm{m} \cdot \mathrm{s}^{-1}$ \\
\hline 293.15 & 1348.68 & 1242.13 \\
298.15 & 1344.13 & 1230.38 \\
303.15 & 1339.61 & 1219.08 \\
308.15 & 1335.11 & 1207.66 \\
313.15 & 1330.63 & 1196.42 \\
318.15 & 1326.16 & 1185.33 \\
323.15 & 1321.70 & 1174.34 \\
328.15 & 1317.26 & 1163.45 \\
333.15 & 1312.83 & 1152.67 \\
338.15 & 1308.41 & 1142.01 \\
343.15 & 1304.01 & 1131.46
\end{tabular}

${ }^{a}$ Standard uncertainty $u(\rho)$ is $\pm 0.05 \mathrm{~kg} \cdot \mathrm{m}^{-3}$. ${ }^{b}$ Standard uncertainty $u(c)$ is $\pm 0.5 \mathrm{~m} \cdot \mathrm{s}^{-1}$ and $u(T)$ is $\pm 0.05 \mathrm{~K}$. temperature dependences of $\rho$ and $c$ are correlated by the use of polynomials of the form

$$
Y(T)=\sum_{i=0}^{2} a_{i}(T-293.15)^{i}
$$

where $Y$ denotes density $\rho$ or speed of sound $c$. The coefficients $a_{i}$ and the mean standard deviations from regression lines (determined by the unweighted least-squares method) are reported in Table S8 of the SI. Both for $\left[\mathrm{C}_{n} \mathrm{C}_{1} \mathrm{im}\right]_{2}\left[\mathrm{Co}(\mathrm{NCS})_{4}\right]$ and for $\left[\mathrm{C}_{n} \mathrm{C}_{1}\right.$ pyr $]\left[\mathrm{NTf}_{2}\right]$, densities are higher for homologues with the 1-butyl alkyl chain in the cation. In the case of the speed of sound, the relation is inverse; i.e., in both cases, the homologues with the 1-butyl- alkyl chain in the cation show lower speed of sound values.

In the case of $\left[\mathrm{C}_{n} \mathrm{C}_{1} \mathrm{im}\right]\left[\mathrm{NTf}_{2}\right](n=3-6)$, the densities and speeds of sound are taken from ref 23 , while in the case of $\left[\mathrm{C}_{n} \mathrm{C}_{1} \mathrm{im}\right]\left[\mathrm{NTf}_{2}\right](n=2,8)$ the data are taken from ref 46 . The isobaric coefficients of thermal expansion are estimated from dependences of the density on temperature; correlation equations reported in this work (Table S8) and in refs 23 and 46 are used.

Table 6 and Table S9 summarize the determined $C_{V}$ and $C_{p} /$ $C_{V}$ values. $C_{V}$ changes with the temperature in the same manner as $C_{p}$; both values differ only by the term $\alpha_{p}^{2} V T \kappa_{T}{ }^{-1}$, which is in practice (taking into account uncertainty) constant within the investigated temperature range. Thus, the ratio of the heat capacities in this relatively narrow temperature range is in practice also nearly constant. The $C_{p}-C_{V}$ values (Figure 6b) are the highest for $\left[\mathrm{C}_{n} \mathrm{C}_{1} \mathrm{im}\right]_{2}\left[\mathrm{Co}(\mathrm{NCS})_{4}\right]$. For the $\left[\mathrm{C}_{n} \mathrm{C}_{1} \mathrm{im}\right]$ $\left[\mathrm{NTf}_{2}\right]$ series $C_{p}-C_{V}$ increases nearly linearly $\left(2.8 \pm 0.2 \mathrm{~J} \cdot \mathrm{K}^{-1}\right.$. $\mathrm{mol}^{-1}$ per $\mathrm{CH}_{2}$ group) with the increasing alkyl side chain length in the cation (Figure 6b). In other words, the increase in $C_{V}$ with the addition of each $\mathrm{CH}_{2}$ group is smaller by $2.8 \mathrm{~J} \cdot \mathrm{K}^{-1}$. $\mathrm{mol}^{-1}$ in relation to the observed increase of $C_{p}$; in the cases of $\left[\mathrm{C}_{n} \mathrm{C}_{1} \mathrm{im}\right]_{2}\left[\mathrm{Co}(\mathrm{NCS})_{4}\right]$ and $\left[\mathrm{C}_{n} \mathrm{C}_{1} \mathrm{pyr}\right]\left[\mathrm{NTf}_{2}\right]$ suitable values are 3.9 and $2.5 \mathrm{~J} \cdot \mathrm{K}^{-1} \cdot \mathrm{mol}^{-1}$ per $\mathrm{CH}_{2}$, respectively.

3.3. Energy Storage Density and Thermal Conductivity. For heat transfer liquids, one of the critical parameters is the energy storage density, also called the volumic heat capacity 
Table 6. Determined by the Use of the Acoustic Method Molar Isochoric Heat Capacities $C_{V}$ within the Temperature Range 293.15-323.15 K at Atmospheric Pressure for ILs Studied

\begin{tabular}{|c|c|c|c|c|c|c|c|}
\hline \multirow[b]{2}{*}{ IL } & \multicolumn{7}{|c|}{$C_{V} / \mathrm{J} \cdot \mathrm{K}^{-1} \cdot \mathrm{mol}^{-1}$ at temperatures $\mathrm{T} / \mathrm{K}$} \\
\hline & 293.15 & 298.15 & 303.15 & 308.15 & 313.15 & 318.15 & 323.15 \\
\hline$\left[\mathrm{C}_{2} \mathrm{C}_{1} \mathrm{im}\right]\left[\mathrm{NTf}_{2}\right]$ & 429.0 & 431.8 & 434.4 & 437.2 & 440.0 & 442.9 & 445.9 \\
\hline$\left[\mathrm{C}_{3} \mathrm{C}_{1} \mathrm{im}\right]\left[\mathrm{NTf}_{2}\right]$ & 454.6 & 457.1 & 459.8 & 462.5 & 465.3 & 468.3 & 471.5 \\
\hline$\left[\mathrm{C}_{4} \mathrm{C}_{1} \mathrm{im}\right]\left[\mathrm{NTf}_{2}\right]$ & 487.9 & 491.2 & 494.4 & 497.4 & 500.2 & 502.9 & 505.5 \\
\hline$\left[\mathrm{C}_{5} \mathrm{C}_{1} \mathrm{im}\right]\left[\mathrm{NTf}_{2}\right]$ & 516.9 & 520.1 & 523.2 & 526.5 & 529.8 & 533.0 & 536.2 \\
\hline$\left[\mathrm{C}_{6} \mathrm{C}_{1} \mathrm{im}\right]\left[\mathrm{NTf}_{2}\right]$ & 544.1 & 547.4 & 550.8 & 554.3 & 557.8 & 561.5 & 565.4 \\
\hline$\left[\mathrm{C}_{7} \mathrm{C}_{1} \mathrm{im}\right]\left[\mathrm{NTf}_{2}\right]$ & 574.6 & 578.3 & 581.9 & 585.6 & 589.3 & 593.0 & 596.8 \\
\hline$\left[\mathrm{C}_{8} \mathrm{C}_{1} \mathrm{im}\right]\left[\mathrm{NTf}_{2}\right]$ & 613.5 & 617.1 & 620.8 & 624.7 & 628.6 & 632.7 & 636.9 \\
\hline$\left[\mathrm{C}_{2} \mathrm{C}_{1} \mathrm{im}\right]_{2}\left[\mathrm{Co}(\mathrm{NCS})_{4}\right]$ & 641.1 & 643.7 & 646.5 & 649.4 & 652.4 & 655.4 & $658.6^{a}$ \\
\hline$\left[\mathrm{C}_{4} \mathrm{C}_{1} \mathrm{im}\right]_{2}\left[\mathrm{Co}(\mathrm{NCS})_{4}\right]$ & 737.3 & 740.6 & 744.2 & 747.9 & 751.8 & 756.2 & $760.9^{a}$ \\
\hline$\left[\mathrm{C}_{3} \mathrm{C}_{1} \mathrm{pyr}\right]\left[\mathrm{NTf}_{2}\right]$ & 492.5 & 495.9 & 499.1 & 502.3 & 505.4 & $508.4^{a}$ & $511.3^{a}$ \\
\hline$\left[\mathrm{C}_{4} \mathrm{C}_{1} \mathrm{pyr}\right]\left[\mathrm{NTf}_{2}\right]$ & 517.5 & 520.6 & 523.7 & 526.9 & 530.3 & 533.8 & $537.7^{a}$ \\
\hline
\end{tabular}

and denoted $C_{p} / V$ (this value can be also easily calculated as the product of the specific heat capacity and density). Based on this property, it has been stated that ILs are even better thermal energy storage liquids than conventional heat transfer liquids. ${ }^{8,48}$ The estimated by Paulechka et al. ${ }^{63}$ average $C_{p} / V$ value (for various $19 \mathrm{ILs}$ ) is equal to $1.95 \pm 0.02 \mathrm{~J} \cdot \mathrm{K}^{-1} \cdot \mathrm{cm}^{-3}$ at $298.15 \mathrm{~K}$. In turn, according to Rocha et al. ${ }^{18}$ the volumic heat capacity for the $\left[\mathrm{C}_{n} \mathrm{C}_{1} \mathrm{im}\right]\left[\mathrm{NTf}_{2}\right]$ series at $298.15 \mathrm{~K}$ shows a gradual decrease from $\left[\mathrm{C}_{2} \mathrm{C}_{1} \mathrm{im}\right]\left[\mathrm{NTf}_{2}\right]$ to $\left[\mathrm{C}_{5} \mathrm{C}_{1} \mathrm{im}\right]\left[\mathrm{NTf}_{2}\right]$ that reaches a constant value of $1.92 \mathrm{~J} \cdot \mathrm{K}^{-1} \cdot \mathrm{cm}^{-3}$ in $\left[\mathrm{C}_{7} \mathrm{C}_{1} \mathrm{im}\right]$ $\left[\mathrm{NTf}_{2}\right]$ to $\left[\mathrm{C}_{12} \mathrm{C}_{1} \mathrm{im}\right]\left[\mathrm{NTf}_{2}\right]$. This is in contrast to works conducted by Paulechka et al. ${ }^{63}$ and Gardas et al. ${ }^{66}$ which show a constant value with incremental increasing carbon number on the alkyl chain. Contrary to specific heat capacities, the volumic heat capacity for $\left[\mathrm{C}_{2} \mathrm{C}_{1} \mathrm{im}\right]_{2}\left[\mathrm{Co}(\mathrm{NCS})_{4}\right]\left(1.896 \mathrm{~J} \cdot \mathrm{K}^{-1} \cdot \mathrm{cm}^{-3}\right)$ is somewhat greater than that for $\left[\mathrm{C}_{4} \mathrm{C}_{1} \mathrm{im}\right]_{2}\left[\mathrm{Co}(\mathrm{NCS})_{4}\right](1.862$ $\left.\mathrm{J} \cdot \mathrm{K}^{-1} \cdot \mathrm{cm}^{-3}\right)$. To clarify this disagreement in relation to the behavior of volumic heat capacity, more accurate measurements for other IL series are needed.

Generally, however, because $C_{p} / V$ is almost independent of the composition of IL, the heat transfer and accumulating IL should be chosen subject to the other parameters, among others thermal conductivity. Unfortunately, there are not yet many experimental determinations of the thermal conductivity of ILs and in practice almost all have been done with transient hot-wire probes, ${ }^{8,67-71}$ with mostly very optimistically claimed uncertainties between 2 and 5\%. Thus, estimation of thermal conductivity $\lambda$ from other easily obtained properties is a good and justifiable choice, at least in the cases of ILs for which there is an entire lack of this type of data. For the determination of $\lambda$ the relation between $\lambda$ and $c$ can be used $(\lambda=a c$, where $a$ is a constant expressed in terms of the various parameters), which is supported by the similarity of the mechanisms of these processes. In this work we estimate thermal conductivity $\lambda$ based on the speed of sound and density using the modified Bridgman equation developed by $\mathrm{Wu}$ et al. $^{72}$ in the form

$$
\lambda=\rho^{2 / 3} M^{1 / 3} c\left(k_{0} M^{\alpha-1} / \rho^{a}+k_{1} T+k_{2}\right)
$$

where $k_{0}, k_{1}, k_{2}$, and $\alpha$ are original constants reported by Wu et al. $^{72}$ For calculations the experimental $\rho$ and $c$ values measured in this work or reported in refs 23 and 46 are used. Table S10 of the SI summarizes the calculated $\lambda$ values for the ILs studied. It appears that, compared to $\left[\mathrm{C}_{n} \mathrm{C}_{1} \mathrm{im}\right]\left[\mathrm{NTf}_{2}\right]$, in the case of $\left[\mathrm{C}_{n} \mathrm{C}_{1} \mathrm{im}\right]_{2}\left[\mathrm{Co}(\mathrm{NCS})_{4}\right]$ with the same alkyl chain in the cation a large increase (about $42 \%$ ) of the $\lambda$ values is observed. In other words, $\left[\mathrm{C}_{n} \mathrm{C}_{1} \mathrm{im}\right]_{2}\left[\mathrm{Co}(\mathrm{NCS})_{4}\right]$ samples show a relatively very high thermal conductivity. According to $\mathrm{Wu}$ et al., ${ }^{72}$ calculations using eq 5 can be made using either experimental $\rho$ and $c$ values or $\rho$ and $c$ values obtained from predictive models. However, when experimental $\rho$ and $c$ values are used, the model slightly underestimates the $\lambda$ values in relation to the values obtained (using $\rho$ and $c$ values determined from predictive models) and reported by $\mathrm{Wu}$ et al. ${ }^{72}$ (Figure 7 ). In

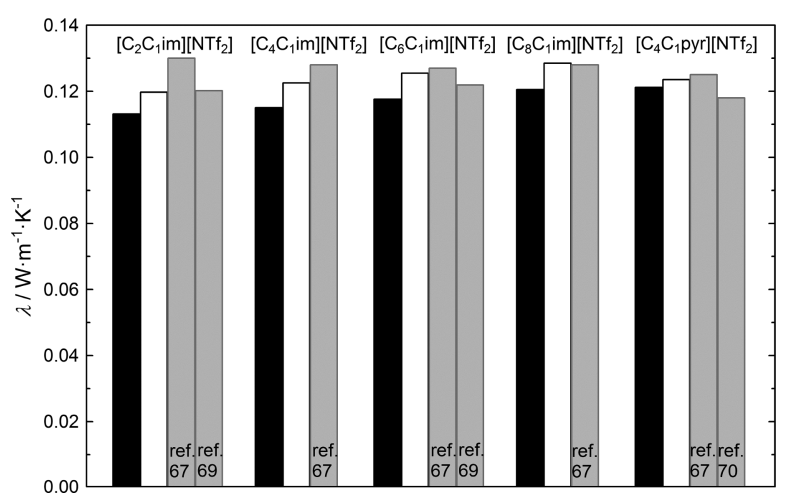

Figure 7. Comparison of thermal conductivity $\lambda$ between experimental data taken from the literature ${ }^{67,69,70}$ (gray bars), calculated data obtained by $\mathrm{Wu}$ et al. $^{72}$ (white bars), and those estimated during this work by eq 5 (black bars) for the selected ILs at $T=293 \mathrm{~K}$.

consequence, the deviations between the calculated values in this work and available experimental $\lambda$ values ${ }^{67,69,70}$ fluctuate between $2.7 \%$ (for $\left[\mathrm{C}_{4} \mathrm{C}_{1}\right.$ pyr $]\left[\mathrm{NTf}_{2}\right]$ at $293 \mathrm{~K}$ ) and $-14 \%$ (for $\left[\mathrm{C}_{2} \mathrm{C}_{1} \mathrm{im}\right]\left[\mathrm{NTf}_{2}\right]$ at $\left.323 \mathrm{~K}\right)$. In other words, these deviations are somewhat higher than the deviations reported by $\mathrm{Wu}$ et al. ${ }^{72}$ calculated using the $\lambda$ values obtained by the use of predictive models for $\rho$ and $c$ (AARDs are ca. 7.3 and 3.0\%, respectively). Thus, although the use of easily accessible experimental $\rho$ and $c$ data leads unfortunately to slightly higher deviations (mostly underestimation) of the calculated $\lambda$ values from the experimental ones, the results are acceptable.

3.4. Thermophysical Material Constants. The isobaric thermal expansion coefficient $\alpha_{p}$, the isothermal compressibility coefficient $\kappa_{T}$, and the isochoric pressure coefficient $\beta_{V}$ form a set of three important fundamental material constants (three so-called thermophysical coefficients). As these quantities are interconnected, usually $\alpha_{p}$ and $\kappa_{T}$ are reported, whereas $\beta_{V}$ can 
be easily obtained as the product $\alpha_{p} \cdot \kappa_{T}^{-1}$. Generally, the $\alpha_{p}$ values of ILs are small. For the ILs studied in this work, the smallest values show $\left[\mathrm{C}_{n} \mathrm{C}_{1} \mathrm{im}\right]_{2}\left[\mathrm{Co}(\mathrm{NCS})_{4}\right]$ (Table S11), where at $298.15 \mathrm{~K}$ the $\alpha_{p}$ values are $5.710 \times 10^{-4}$ and $5.798 \times$ $10^{-4} \mathrm{~K}^{-1}$ for homologues with $n=2$ and 4, respectively. In the case of $\left[\mathrm{C}_{n} \mathrm{C}_{1} \mathrm{im}\right]\left[\mathrm{NTf}_{2}\right]$ series, the $\alpha_{p}$ values changes irregularly with the increasing alkyl chain length in the cation and lie in the range $(6.656-6.733) \times 10^{-4} \mathrm{~K}^{-1}$. For all ILs studied, the changes with the temperature are hardly perceptible; therefore in practice $\alpha_{p}$ can be considered as nearly constant in the analyzed $T$ range.

The dark blue paramagnetic $\left[\mathrm{C}_{n} \mathrm{C}_{1} \mathrm{im}\right]_{2}\left[\mathrm{Co}(\mathrm{NCS})_{4}\right]$ have also unexpected low $\kappa_{T}$ values which were stated already in the preliminary studies. ${ }^{20}$ For this reason these ILs have been proposed in the mentioned study by some of us as potential hydraulic fluids. $^{20}$ In all three series of ILs studied, $\kappa_{T}$ (calculated according to eq 3) increases with the increasing alkyl chain length in the cation (Figure 8 and Table 7). In other

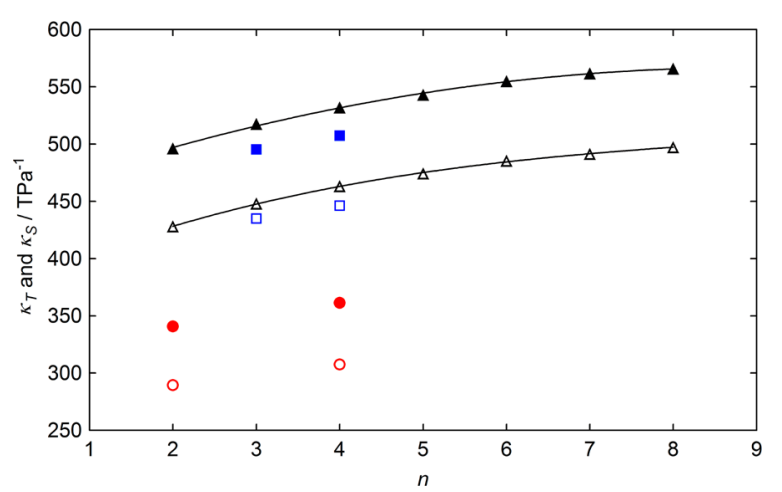

Figure 8. Effect of alkyl chain length, $n$, in the cation on the compressibility at $T=298.15 \mathrm{~K}$ for $\boldsymbol{\Lambda}$ and $\triangle,\left[\mathrm{C}_{n} \mathrm{C}_{1} \mathrm{im}\right]\left[\mathrm{NTf}_{2}\right]$; and $\square,\left[\mathrm{C}_{n} \mathrm{C}_{1}\right.$ pyr $]\left[\mathrm{NTf}_{2}\right]$; as well as $\mathrm{O}$ and $\bullet,\left[\mathrm{C}_{n} \mathrm{C}_{1} \mathrm{im}\right]_{2}\left[\mathrm{Co}(\mathrm{NCS})_{4}\right]$, where the filled symbols and the open symbols represent isothermal $\kappa_{T}$ and isentropic $\kappa_{S}$ compressibility coefficients, respectively. $\kappa_{S}$ values for $n=2$ and 8 as well as $n=3-5$ of the $\left[\mathrm{C}_{n} \mathrm{C}_{1} \mathrm{im}\right]\left[\mathrm{NTf}_{2}\right]$ series taken from refs 46 and 23, respectively. As in the case of $n=6$, the $\kappa_{S}$ values reported in Table S7 in ref 23 are misprinted; the recalculated $\kappa_{S}$ value (from original $\rho$ and $c$ data $^{23}$ ) is used. Lines are arbitrary and are a guide for the eye.

words, the lower members of the homologous series show enhanced structural rigidity in comparison to the higher members. Moreover, in each case the temperature rise leads to an increase of compressibility. For the $\left[\mathrm{C}_{n} \mathrm{C}_{1} \mathrm{im}\right]\left[\mathrm{NTf}_{2}\right]$ series, this increase with the increasing carbon number $n$ becomes less pronounced. In the same manner $\kappa_{S}$ changes. However, the $\kappa_{S}$ values are roughly $12-15 \%$ lower than the $\kappa_{T}$ values (Figure 8). Table S12 of the SI summarizes the $\kappa_{S}$ values obtained in this work for $\left[\mathrm{C}_{7} \mathrm{C}_{1} \mathrm{im}\right]\left[\mathrm{NTf}_{2}\right],\left[\mathrm{C}_{n} \mathrm{C}_{1} \mathrm{pyr}\right]\left[\mathrm{NTf}_{2}\right]$, and $\left[\mathrm{C}_{n} \mathrm{C}_{1} \mathrm{im}\right]_{2}\left[\mathrm{Co}(\mathrm{NCS})_{4}\right]$.

An additional interesting property is the internal pressure $P_{\text {int }}$ that can be calculated easily from the following relation:

$$
P_{\text {int }}=T \beta_{V}-p
$$

where $p$ is generally an external pressure; in our case it is atmospheric pressure. Although at low pressures, mostly at atmospheric pressure, the second term in eq 6 can be neglected without significant error $\left(p \ll T \beta_{V}\right)$, it must always be included at high pressures. ${ }^{3,25,73,74}$ Although $P_{\text {int }}$ can be obtained from direct measurements of $\beta_{V}$ or equations of state, one of the more convenient and well-established methods is the indirect acoustic method $\left(\beta_{V}\right.$ is obtained through $\kappa_{T}$ calculated by eq $3)^{75,76}$ The $P_{\text {in }}$ values calculated in this way are collected in Table S13 of the SI. It appears that $P_{\text {int }}$ decreases with increasing temperature for all ILs studied. The negative $\left(\partial P_{\text {int }}\right)$ $\partial T)_{p}$ values at atmospheric pressure are typical for molecular organic liquids with the exception of substances which form a spatial network of $\mathrm{H}$-bonds (e.g., some polyols, ${ }^{73,74,77,78}$ water $\left.{ }^{78,79}\right)$ where the positive $\left(\partial P_{\text {int }} / \partial T\right)_{p}$ values occur. Contrary to compressibility, $P_{\text {int }}$ decreases for higher members of the homologous series (Figure 9). As this property is a measure of cohesive forces, it can be concluded that molecular cohesion decreases for higher members of the homologous series and structures are simultaneously more compressible in accordance with increasing compressibility for higher members of the homologous series. Interestingly, in the case of molecular liquids, $P_{\text {int }}$ values tend to increase in a homologous series with the number of carbon atoms (e.g., in 1-alkanols ${ }^{75}$ ). However, as was stated very recently, the detailed interpretation of the $P_{\text {int }}$ in ILs is difficult and an open question. ${ }^{80}$

3.5. Modeling the $C_{p}$ Values. The $C_{p}$ data of the investigated ILs have been evaluated at temperatures 298.15 and $323.15 \mathrm{~K}$ by using the Preiss method ${ }^{22}$ implemented in the COSMOthermX Ionic Liquids Properties option. ${ }^{34}$ Briefly, according to Preiss et al. ${ }^{22}$ the $C_{p}$ values of ILs can be determined thanks to prior knowledge of their molar volume, $V_{\mathrm{m}}$, values according to the following linear relationship:

Table 7. Isothermal Compressibility Coefficients $\kappa_{T}$ at Temperatures $T$ for ILs Studied

\begin{tabular}{|c|c|c|c|c|c|c|c|}
\hline \multirow[b]{2}{*}{ IL } & \multicolumn{7}{|c|}{$\kappa_{T} / \mathrm{TPa}^{-1}$ at temperatures $\mathrm{T} / \mathrm{K}$} \\
\hline & 293.15 & 298.15 & 303.15 & 308.15 & 313.15 & 318.15 & 323.15 \\
\hline$\left[\mathrm{C}_{2} \mathrm{C}_{1} \mathrm{im}\right]\left[\mathrm{NTf}_{2}\right]$ & 485.8 & 496.0 & 506.2 & 516.6 & 527.2 & 537.9 & 548.7 \\
\hline$\left[\mathrm{C}_{3} \mathrm{C}_{1} \mathrm{im}\right]\left[\mathrm{NTf}_{2}\right]$ & 506.8 & 517.4 & 528.2 & 539.1 & 550.2 & 561.5 & 572.9 \\
\hline$\left[\mathrm{C}_{4} \mathrm{C}_{1} \mathrm{im}\right]\left[\mathrm{NTf}_{2}\right]$ & 521.0 & 531.8 & 542.9 & 554.1 & 565.6 & 577.3 & 589.2 \\
\hline$\left[\mathrm{C}_{5} \mathrm{C}_{1} \mathrm{im}\right]\left[\mathrm{NTf}_{2}\right]$ & 531.6 & 542.9 & 554.5 & 566.3 & 578.3 & 590.5 & 603.0 \\
\hline$\left[\mathrm{C}_{6} \mathrm{C}_{1} \mathrm{im}\right]\left[\mathrm{NTf}_{2}\right]$ & 543.1 & 554.8 & 566.7 & 578.8 & 591.1 & 603.6 & 616.3 \\
\hline$\left[\mathrm{C}_{7} \mathrm{C}_{1} \mathrm{im}\right]\left[\mathrm{NTf}_{2}\right]$ & 549.7 & 561.6 & 573.5 & 585.9 & 598.3 & 611.1 & 624.0 \\
\hline$\left[\mathrm{C}_{8} \mathrm{C}_{1} \mathrm{im}\right]\left[\mathrm{NTf}_{2}\right]$ & 553.0 & 565.6 & 578.5 & 591.5 & 604.7 & 618.0 & 631.4 \\
\hline$\left[\mathrm{C}_{2} \mathrm{C}_{1} \mathrm{im}\right]_{2}\left[\mathrm{Co}(\mathrm{NCS})_{4}\right]$ & 335.1 & 340.8 & 346.5 & 352.3 & 358.1 & 363.9 & $369.8^{a}$ \\
\hline$\left[\mathrm{C}_{4} \mathrm{C}_{1} \mathrm{im}\right]_{2}\left[\mathrm{Co}(\mathrm{NCS})_{4}\right]$ & 355.2 & 361.4 & 367.6 & 373.9 & 380.1 & 386.5 & $392.9^{a}$ \\
\hline$\left[\mathrm{C}_{3} \mathrm{C}_{1} \mathrm{pyr}\right]\left[\mathrm{NTf}_{2}\right]$ & 485.7 & 495.3 & 505.2 & 515.3 & 525.6 & $536.3^{a}$ & $547.3^{a}$ \\
\hline$\left[\mathrm{C}_{4} \mathrm{C}_{1} \mathrm{pyr}\right]\left[\mathrm{NTf}_{2}\right]$ & 497.1 & 507.3 & 517.7 & 528.2 & 538.9 & 549.7 & $560.7^{a}$ \\
\hline
\end{tabular}

${ }^{a}$ Calculated using extrapolated $c$ values. 


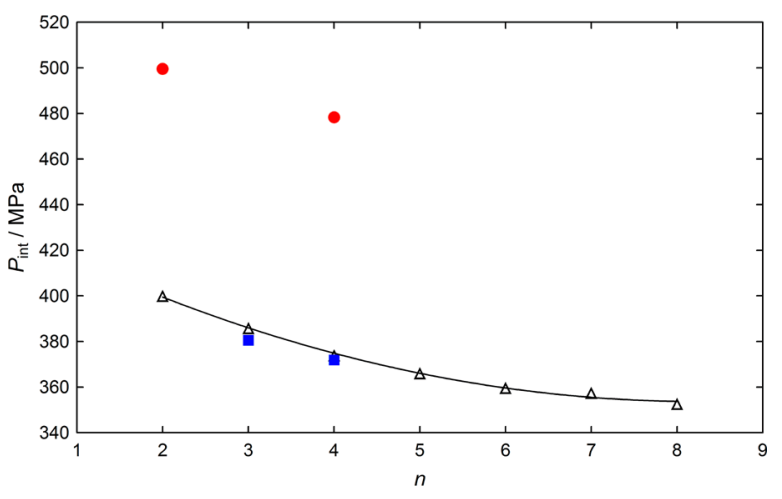

Figure 9. Effect of the alkyl chain length, $n$, in the cation on the internal pressure $P_{\text {int }}$ at $T=298.15 \mathrm{~K}$ for $\triangle,\left[\mathrm{C}_{n} \mathrm{C}_{1} \mathrm{im}\right]\left[\mathrm{NTf}_{2}\right]$; $\left[\mathrm{C}_{n} \mathrm{C}_{1}\right.$ pyr $]\left[\mathrm{NTf}_{2}\right]$; and $\bullet,\left[\mathrm{C}_{n} \mathrm{C}_{1} \mathrm{im}\right]_{2}\left[\mathrm{Co}(\mathrm{NCS})_{4}\right] . \rho$ and $c$ values for calculations in the cases of $n=2$ and 8 as well as $n=3-6$ of the $\left[\mathrm{C}_{n} \mathrm{C}_{1} \mathrm{im}\right]\left[\mathrm{NTf}_{2}\right]$ series taken from refs 46 and 23 , respectively. The line is arbitrary and is a guide for the eye.

$$
C_{p}(T)=\alpha_{T} V_{\mathrm{m}}+\beta_{T}
$$

where $C_{p}(T)$ is the heat capacity of the IL estimated at $T=$ $298.15 \mathrm{~K}$ or $T=323.15 \mathrm{~K} . \alpha_{T}$ and $\beta_{T}$ are the temperature dependent correlation parameters determined by Preiss et al. ${ }^{22}$ as reported in Table S14 of the SI. $V_{\mathrm{m}}$ is the molecular volume $\left(\mathrm{nm}^{3}\right)$ of the IL calculated by using COSMOthermX thanks to the following equation:

$$
V_{\mathrm{m}}=\sum V_{\text {ion }}
$$

where $V_{\text {ion }}\left(\mathrm{nm}^{3}\right)$ is the molecular volume of each ion of the IL.

The molecular volume of each ion has been determined by using the methodology reported by Preiss et al. ${ }^{22}$ which is based on the prior knowledge of the COSMO Volume of each ion, $V_{\text {ion }}^{\text {COSMO }}$

$$
V_{\text {ion }}=\delta_{\text {ion }} V_{\text {ion }}^{\text {COSMO }}+\varepsilon_{\text {ion }}
$$

where $\delta_{\text {ion }}$ and $\varepsilon_{\text {ion }}$ are the ion dependent correlation parameters determined by Preiss et al. $^{22}$ as reported in Table S14 of the SI.

Using this methodology, ${ }^{22,34}$ the sigma profiles, the COSMO Volumes, and then the molecular volumes (eq 9) of selected ions have been determined by using COSMOthermX as reported in Table S15 of the SI. Then, the molecular volumes of selected ILs, as well as their isobaric heat capacities at $T=$ 293.15 $\mathrm{K}$ and $T=323.15 \mathrm{~K}$, have been estimated using eqs $7-9$ as reported in Table S16 of the SI. A comparison between experimental heat capacity data $\left(C_{p, \exp }(T)\right)$ determined herein at $T=293.15 \mathrm{~K}$ and $T=323.15 \mathrm{~K}$ with those estimated $\left(C_{p, \text { calc }}(T)\right)$ using the COSMOthermX Ionic Liquids Properties option $^{22,34}$ was then carried out by determining in each case the relative deviation, $\mathrm{RD}\left(\mathrm{RD}=100\left(C_{p, \text { calc }}(T)-C_{p, \exp }(T)\right) /\right.$ $\left.\left(C_{p \text {,exp }}(T)\right)\right)$, listed in Table S16 of the SI.

As reported in Table S16 of the SI and illustrated in Figure 10 , except in the case of the estimation of the $C_{p}(323.15 \mathrm{~K})$ of $\left[\mathrm{C}_{2} \mathrm{C}_{1} \mathrm{im}\right]_{2}\left[\mathrm{Co}(\mathrm{NCS})_{4}\right]$, all $\mathrm{RD}$ values are negative showing that COSMOthermX calculations underestimated the $C_{p}$ whatever the temperature and the IL structure. However, as already claimed by Preiss et al. ${ }^{22}$ for other IL structures and as shown herein in Figure 11, such deviations seem to decrease by increasing the temperature. For example, AARDs (between $C_{p, \text { calc }}(T)$ and $C_{p, \exp }(\mathrm{T})$ data) close to 3.4 and $2.3 \%$ were calculated at 298.15 and $323.15 \mathrm{~K}$, respectively. Overall, as
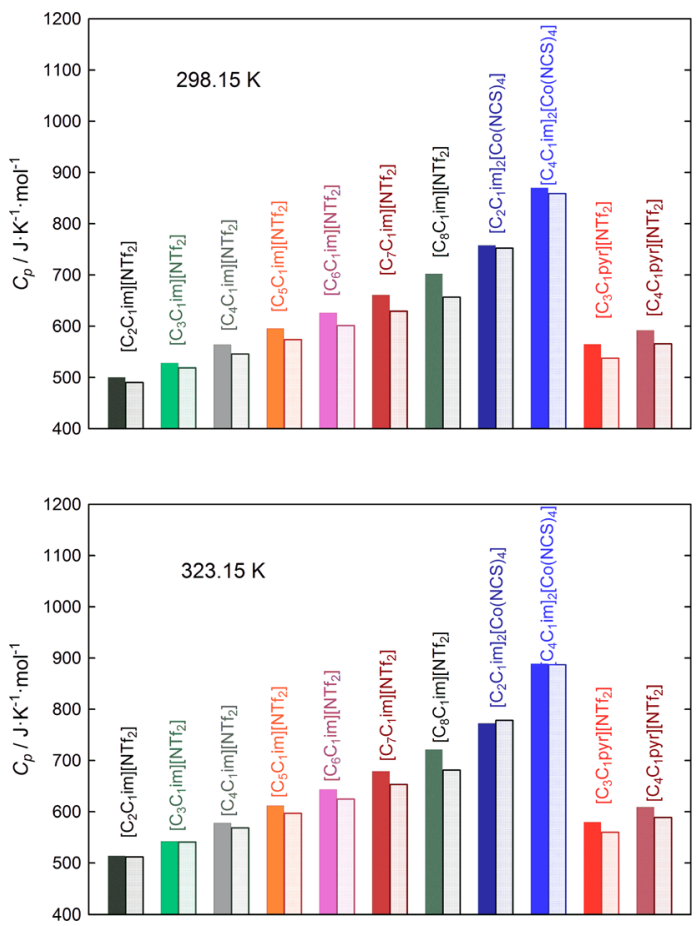

Figure 10. Comparison of values of molar isobaric heat capacity $C_{p}$ at (upper) $T=298.15 \mathrm{~K}$ and (lower) $T=323.15 \mathrm{~K}$ of the investigated ILs between experimental data reported during this work (filled bars) and those estimated (empty bars) by COSMOthermX. ${ }^{22,34}$
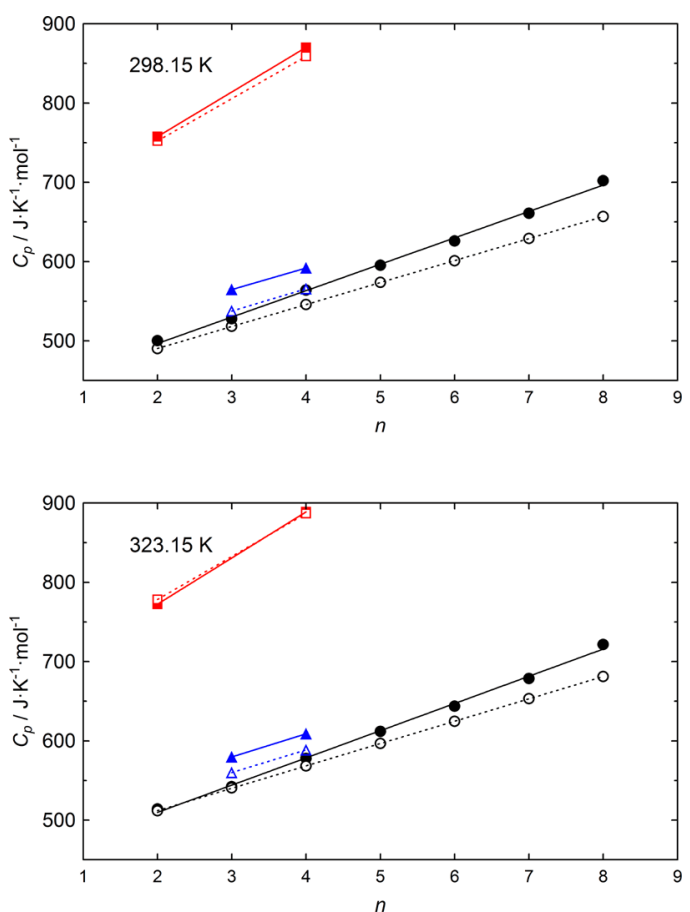

Figure 11. Effect of alkyl chain length, $n$, on the predictive capability of the Preiss et al. ${ }^{22}$ method at (upper) $T=298.15 \mathrm{~K}$ and (lower) $T=$ $323.15 \mathrm{~K}$ for $(\bullet, O)\left[\mathrm{C}_{n} \mathrm{C}_{1} \mathrm{im}\right]\left[\mathrm{NTf}_{2}\right],(\boldsymbol{\Delta}, \triangle)\left[\mathrm{C}_{n} \mathrm{C}_{1} \mathrm{pyr}\right]\left[\mathrm{NTf}_{2}\right]$, and $(\boldsymbol{\square}, \square)\left[\mathrm{C}_{n} \mathrm{C}_{1} \mathrm{im}\right]_{2}\left[\mathrm{Co}(\mathrm{NCS})_{4}\right]$, where the filled symbols and solid lines and the open symbols and dashed lines represent experimental data and those estimated by COSMOthermX, respectively.

claimed by Preiss et al., ${ }^{22}$ good agreements, with an AARD close to $2.8 \%$, were observed between experimental and estimated data. Furthermore, whatever the temperature, 
calculated $C_{p}$ data of $\left[\mathrm{C}_{3} \mathrm{C}_{1} \mathrm{pyr}\right]\left[\mathrm{NTf}_{2}\right],\left[\mathrm{C}_{2} \mathrm{C}_{1} \mathrm{im}\right]\left[\mathrm{NTf}_{2}\right]$, $\left[\mathrm{C}_{4} \mathrm{C}_{1} \mathrm{im}\right]\left[\mathrm{NTf}_{2}\right]$, and $\left[\mathrm{C}_{6} \mathrm{C}_{1} \mathrm{im}\right]\left[\mathrm{NTf}_{2}\right]$ determined during this work are all in good agreement with those reported by Preiss et al. ${ }^{22}$ (e.g., at $298.15 \mathrm{~K}, C_{p}=541,494,550$, and $605 \mathrm{~J}$. $\mathrm{mol}^{-1} \cdot \mathrm{K}^{-1}$, respectively), showing that the Preiss et al. ${ }^{22}$ method is accurately implemented within COSMOthermX. ${ }^{34}$

To assess this implemented method in greater detail, the effect of the alkyl chain length on the cation on its predictive capacity was then illustrated in Figure 11. As shown in Figure 11, larger deviations between experimental and estimated $C_{p}$ data were observed by increasing the alkyl chain length $(n)$ on the 1-alkyl-3-methylimidazolium cation. This behavior is probably due to a propagation of errors on fitting parameters originally proposed by Preiss et al. ${ }^{22}$ during both the $V_{\mathrm{m}}$ and $C_{p}$ calculations (eqs 7-9) which tends to increase when the alkyl chain length on the cation structure increases. Furthermore, as seen in Figure 11, by keeping constant the alkyl chain length attached on each cation, $C_{p}$ data of imidazolium-based ILs seem to be more accurately estimated by COSMOthermX than the pyrrolidinium ones. In other words, to improve the predictive capacity of such a method, more accurate fitting parameters must be determined by using a larger set of recommended data for various IL structures. Nevertheless, prior to being able to assess this possibility, more accurate heat capacity and molecular volume data are requested for a larger range of ILs. However, and more interestingly, whatever the IL structure and the temperature, by using the Preiss et al. ${ }^{22}$ method within COSMOthermX, very good estimations were observed in the case of the $\left[\mathrm{Co}(\mathrm{NCS})_{4}\right]^{2-}$-based ILs (e.g., RDs close to -0.7 and $-1.3 \%$ were found for $\left[\mathrm{C}_{2} \mathrm{C}_{1} \mathrm{im}\right]_{2}\left[\mathrm{Co}(\mathrm{NCS})_{4}\right]$ and $\left[\mathrm{C}_{4} \mathrm{C}_{1} \mathrm{im}\right]_{2}\left[\mathrm{Co}(\mathrm{NCS})_{4}\right]$ at $298.15 \mathrm{~K}$, respectively) showing that the metafile approach used during this work could be applied to estimate accurately the $C_{\mathrm{p}}$ for this particular IL series. However, to fully assess the accuracy of this method, further data sets of other non-single-charged-ion-based ILs are requested. Alternatively, this metafile-based approach could be applied for other physical properties (viscosity, molecular volume, etc.) of non-single-charged ions using COSMOthermX to verify its predictive capability.

\section{SUMMARY}

The isobaric heat capacities in the temperature range from 293.15 to $323.15 \mathrm{~K}$ for $11 \mathrm{ILs}$ are reported; in the case of four ILs $\left(\left[\mathrm{C}_{5} \mathrm{C}_{1} \mathrm{im}\right]\left[\mathrm{NTf}_{2}\right], \quad\left[\mathrm{C}_{7} \mathrm{C}_{1} \mathrm{im}\right]\left[\mathrm{NTf}_{2}\right], \quad\left[\mathrm{C}_{2} \mathrm{C}_{1} \mathrm{im}\right]_{2}[\mathrm{Co}-\right.$ $\left.(\mathrm{NCS})_{4}\right]$, and $\left.\left[\mathrm{C}_{4} \mathrm{C}_{1} \mathrm{im}\right]_{2}\left[\mathrm{Co}(\mathrm{NCS})_{4}\right]\right)$ the $C_{p}$ data have been not reported in the available literature to date. Moreover, for the last three of them also $c$ and $\kappa_{S}$ data are reported for the first time. In the case of the $\left[\mathrm{C}_{n} \mathrm{C}_{1} \mathrm{im}\right]\left[\mathrm{NTf}_{2}\right]$ series, no odd and even effect of the alkyl chain length in the imidazolium ring of the cation on $C_{p}$ is observed. At the same time consistent $C_{V}$ values together with the $\alpha_{p}$ and $\kappa_{T}$ values for all of the studied ILs are reported. In all three series of ILs studied, enhanced rigidity structures (smaller compressibility) for the lower members of the homologous series are observed. Contrary to compressibility, $P_{\text {int }}$ decreases for the higher members of the homologous series.

Comparison of the available data shows that, in many cases, the scattering of the $C_{p}$ results exceeds the declared uncertainty reported in original works. It seems that, apart from impurities (especially water), deviations observed in the literature $C_{p}$ values reported by various authors are mainly connected to the instrumentation problems. Generally, mostly the data obtained by the use of DSC with very small samples $(\leq 0.1 \mathrm{~mL})$ enclosed in one-way sample pans show the greatest deviations that are well outside of the declared uncertainties. Undoubtedly also the scanning rate has great influence; i.e., it is known that higher speed scanning leads to greater uncertainty. It is not surprising because in such conditions inadequate thermal equilibration can be present. Also the viscosity and thermal conductivity of the samples are probably important factors and should be taken into account in the planning of experiments. In contrast to DSC results obtained with small samples and speed scan rates, the TC DSC results obtained with relatively large samples of ILs (several milliliters) and slow scan rates give more reliable values that are very consistent with AC and DC results. Similar conclusions were stated already previously by other authors. ${ }^{39,60,61}$ At the same time, because the obtained heat capacity can depend also on the previous "history" of the sample, ${ }^{26}$ for example on the fact that the sample was cooled down below the melting point, the samples used should not have such a "history". It seems also necessary that in future works reporting the data on $C_{p}$ values of ILs, more attention should be given to checking the performance of the calorimeters and/or measuring procedures used; in the case of DSC, speed scan rates (of the order of $1 \mathrm{~K} \cdot \mathrm{min}^{-1}$ and higher) and very small samples $(\leq 0.1 \mathrm{~mL})$ should be avoided. A good solution is the TC DSC.

It has also been shown that COSMOthermX calculations underestimated the $C_{p}$ values whatever the temperature and the IL structure. At the same time, it has been shown that the approach used during this work may also be applied to estimate the physical properties (heat capacity, molecular volume, etc.) of non-single-charged ions using COSMOthermX. However, this requires more investigation prior to being able to truly assess its predictive capability.

It appears also that thermal conductivity estimation based on the Bridgman equation modified by $\mathrm{Wu}$ et al. ${ }^{72}$ and using experimental density and speed of sound data lead to rather only a slight underestimation in results.

\section{ASSOCIATED CONTENT}

\section{Supporting Information}

The Supporting Information is available free of charge on the ACS Publications website at DOI: 10.1021/acs.iecr.6b04780.

Coefficients $A_{\mathrm{i}}$ of the $C_{p}$ dependence on temperature; literature values of $C_{p}$ at 293.15 and $323.15 \mathrm{~K}$ along with calorimeter type; coefficients $a_{\mathrm{i}}$ of the $\rho$ and $c$ dependences on temperature; values of $c, C_{p} / C_{V}, \lambda, \alpha_{p}$, $\kappa_{S}$, and $P_{\text {int; }}$ Preiss et al. ${ }^{22}$ parameters; sigma profiles, COSMO Volumes and molecular volumes using COSMO-weight software (PDF)

\section{AUTHOR INFORMATION}

\section{Corresponding Author}

*E-mail: emz@ich.us.edu.pl. Tel.: +48 323591625. Fax: +48 322599978.

ORCID

Edward Zorębski: 0000-0001-8152-6693

\section{Notes}

The authors declare no competing financial interest.

\section{ACKNOWLEDGMENTS}

The authors are grateful to Prof. A. Heintz from the University of Rostock (Germany) for donating the test samples of 
$\left[\mathrm{C}_{2} \mathrm{C}_{1} \mathrm{im}\right]_{2}\left[\mathrm{Co}(\mathrm{NCS})_{4}\right]$ and $\left[\mathrm{C}_{4} \mathrm{C}_{1} \mathrm{im}\right]_{2}\left[\mathrm{Co}(\mathrm{NCS})_{4}\right]$. The authors are profoundly indebted to Ms. J. Skowronek for her participation during the manuscript preparation. P.G. and J.J. acknowledge gratefully the CEA le Ripault (Grant 4600261677/P6E31) and the Engineering and Physical Sciences Research Council (EPSRC) for supporting this work financially (EPSRC First Grant Scheme, Grant EP/M021785/ $1)$.

\section{REFERENCES}

(1) Wilhelm, E. What you Always Wanted to Know about Heat Capacities, but were Afraid to Ask. J. Solution Chem. 2010, 39, 17771818.

(2) Zorębski, E. The Effect of Pressure and Temperature on the Second-Order Derivatives of the Free Energy Functions for Lower Alkanediols. Int. J. Thermophys. 2014, 35, 890-913.

(3) Zorębski, E.; Dzida, M.; Wysocka, E. Acoustic and Thermodynamic Properties of 2-Ethyl-1-Hexanol by Means of High-Pressure Speed of Sound Measurements at Temperatures from (293 to 318) K and Pressures up to $101 \mathrm{MPa}$. J. Chem. Eng. Data 2011, 56, 26802686.

(4) Valencia, J. L.; Gonzalez-Salgado, D.; Troncoso, J.; Peleteiro, J.; Carballo, E.; Romaní, L. Thermophysical Characterization of Liquids Using Precise Density and Isobaric Heat Capacity Measurements As a Function of Pressure. J. Chem. Eng. Data 2009, 54, 904-915.

(5) González-Salgado, D.; Peleteiro, J.; Troncoso, J.; Carballo, E.; Romaní, L.; Bessières, D. Heat Capacities, Densities, and Speeds of Sound for $\{(1,5$-Dichloropentane or 1,6-Dichlorohexane $)+$ Dodecane\}. J. Chem. Eng. Data 2004, 49, 333-338.

(6) Perkins, A. R.; Magee, J. W. Molar Heat Capacity at Constant Volume for Isobutane at Temperatures from (114 to 345$) \mathrm{K}$ and at Pressures to 35 MPa. J. Chem. Eng. Data 2009, 54, 2646-2655.

(7) Wilhelm, E.Heat Capacities: Introduction, Concepts and Selected Applications. In Heat Capacities. Liquids, Solutions and Vapours; Wilhelm, E., Letcher, T. M., Eds.; RSC Publishing: Cambridge, U.K., 2010.

(8) Liu, H.; Maginn, E.; Visser, A. E.; Bridges, N. J.; Fox, E. B. Thermal and Transport Properties of Six Ionic Liquids: An Experimental and Molecular Dynamics Study. Ind. Eng. Chem. Res. 2012, 51, 7242-7254.

(9) Gómez, E.; Calvar, N.; Domínguez, Á.; Macedo, E. A. Thermal Analysis and Heat Capacities of 1-Alkyl-3-methylimidazole Liquids with $\mathrm{NTf}_{2}^{-}, \mathrm{TFO}^{-}$, and $\mathrm{DCA}^{-}$Anions. Ind. Eng. Chem. Res. 2013, 52, 2103-2110.

(10) Chernikova, E. A.; Glukhov, L. M.; Krasovskiy, V. G.; Kustov, L. M.; Vorobyeva, M. G.; Koroteev, A. A. Ionic Liquids as Heat Transfer Fluids: Comparison with Known Systems, Possible Applications, Advantages and Disadvantages. Russ. Chem. Rev. 2015, 84, 875-890.

(11) Jacquemin, J.; Feder-Kubis, J.; Zorębski, M.; Grzybowska, K.; Chorążewski, M.; Hensel-Bielówka, S.; Zorębski, E.; Paluch, M.; Dzida, M. Structure and Thermal Properties of Salicylate-Based-Protic Ionic Liquids as New Heat Storage Media. COSMO-RS Structure Characterization and Modeling of Heat Capacities. Phys. Chem. Chem. Phys. 2014, 16, 3549-3557.

(12) Crosthwaite, J. M.; Muldoon, M. J.; Dixon, J. K.; Anderson, J. L.; Brennecke, J. F. Phase Transition and Decomposition Temperatures, Heat Capacities and Viscosities of Pyridinium Ionic Liquids. J. Chem. Thermodyn. 2005, 37, 559-568.

(13) Ge, R.; Hardacre, C.; Jacquemin, J.; Nancarrow, P.; Rooney, D. Heat Capacities of Ionic Liquids as a Function of Temperature at 0.1 MPa. Measurement and Prediction. J. Chem. Eng. Data 2008, 53, 2148-2153.

(14) Chatel, G.; Leclerc, L.; Naffrechoux, E.; Bas, C.; Kardos, N.; Goux-Henry, C.; Andrioletti, B.; Draye, M. Ultrasonic Properties of Hydrophobic Bis(trifluoromethylsulfonyl)imide-Based Ionic Liquids. J. Chem. Eng. Data 2012, 57, 3385-3390.
(15) Nieto de Castro, C. A. Thermophysical Properties of Ionic Liquids: Do we Know how to Measure them Accurately? J. Mol. Liq. 2010, 156, 10-17.

(16) Nunes, V. M. B.; Lourenço, M. J. V.; Santos, F. J. V.; Matos Lopes, M. M. S.; Nieto de Castro, C. A. Accurate Measurements of Physico-Chemical Properties on Ionic Liquids and Molten Salts. In Seddon, K. E., Gaune-Escard, M., Eds.; Ionic Liquids and Molten Salts: Never the Twain; John Wiley: 2010.

(17) Ionic Liquids Database - IL Thermo (v2.0). http://ilthermo. boulder.nist.gov.

(18) Rocha, M. A. A.; Bastos, M.; Coutinho, J. A. P.; Santos, L. M. N. B. F. Heat Capacities at $298.15 \mathrm{~K}$ of the Extended $\left[\mathrm{CnC}_{1} \mathrm{im}\right]\left[\mathrm{Ntf}_{2}\right]$ Ionic Liquid Series. J. Chem. Thermodyn. 2012, 53, 140-143.

(19) Gómez, E.; Calvar, N.; Macedo, E. A.; Domínguez, Á. Effect of the Temperature on the Physical Properties of Pure 1-Propyl-3methylimidazolium Bis(trifluoromethylsulfonyl)imide and Characterization of its Binary Mixtures with Alcohols. J. Chem. Thermodyn. 2012, $45,9-15$.

(20) Dzida, M.; Zorębski, E.; Chorążewski, M.; Heintz, A. Compressibility of Ionic Liquids as a Hydraulic Fluids. Przem. Chem. 2013, 92, 1595-1597 (in Polish).

(21) Hensel-Bielówka, S.; Wojnarowska, Z.; Dzida, M.; Zorębski, E.; Zorębski, M.; Geppert-Rybczyńska, M.; Peppel, T.; Grzybowska, K.; Wang, Y.; Sokolov, A. P.; Paluch, M. Heterogeneous Nature of Relaxation Dynamics of Room-Temperature Ionic Liquids $(\text { EMim })_{2}\left[\mathrm{Co}(\mathrm{NCS})_{4}\right]$ and $(\mathrm{BMim})_{2}\left[\mathrm{Co}(\mathrm{NCS})_{4}\right]$. J. Phys. Chem. C 2015, 119, 20363-20368.

(22) Preiss, U. P. R. M.; Slattery, J. M.; Krossing, I. In Silico Prediction of Molecular Volumes, Heat Capacities, and TemperatureDependent Densities of Ionic Liquids. Ind. Eng. Chem. Res. 2009, 48, 2290-2296.

(23) Zorębski, M.; Zorębski, E.; Dzida, M.; Skowronek, J.; Jężak, S.; Goodrich, P.; Jacquemin, J. Ultrasonic Relaxation Study of 1-Alkyl-3Methylimidazolium-Based Room Temperature Ionic Liquids: Probing the Role of Alkyl Chain Length in the Cation. J. Phys. Chem. B 2016, 120, 3569-3581.

(24) Peppel, T.; Köckerling, M.; Geppert-Rybczyńska, M.; Ralys, R. V.; Lehmann, J. K.; Verevkin, S. P.; Heintz, A. Low-Viscosity Paramagnetic Ionic liquids with Doubly Charged $\left[\mathrm{Co}(\mathrm{NCS})_{4}\right]^{2-}$ Ions. Angew. Chem., Int. Ed. 2010, 49, 7116-7119.

(25) Chorążewski, M.; Dzida, M.; Zorębski, E.; Zorębski, M. Density, Speed of Sound, Heat Capacity, and Related Properties of 1-Hexanol and 2-Ethyl-1-Butanol as Function of Temperature and Pressure. $J$. Chem. Thermodyn. 2013, 58, 389-397.

(26) Růžička, K.; Fulem, M.; Růžička, V.; Zábranský, M. Heat Capacities of Alkanols: III. Some 1-Alkanols from $\mathrm{C}_{10}$ to $\mathrm{C}_{20}$. Thermochim. Acta 2004, 421, 35-41.

(27) Höhne, G.; Hemminger, W.; Flammersheimer, H.-J. Differential Scanning Calorimetry, An Introduction for Practitioners; Springer-Verlag: Berlin, 1996.

(28) Zorębski, E.; Góralski, P. Molar Heat Capacities for (1-Butanol + 1,4-Butanediol, 2,3-Butanediol, 1,2-Butanediol, and 2-Methyl-2,4Pentanediol) as Function of Temperature. J. Chem. Thermodyn. 2007, 39, 1601-1607.

(29) Zábranský, M.; Kolská, Z.; Růžička, V., Jr.; Domalski, E. S. Heat Capacity of Liquids: Critical Review and Recommended Values. Supplement II. J. Phys. Chem. Ref. Data 2010, 39, 013103.

(30) Paramo, R.; Zouine, M.; Sobrón, F.; Casanova, C. Saturated Heat Capacities of Some Linear and Branched Alkyl-Benzenes between 288 and $348 \mathrm{~K}$. Int. J. Thermophys. 2003, 24, 185-189.

(31) Zorebski, E.; Deć, E. Speeds of Sound and Isentropic Compressibilities for Binary Mixtures of 1,2-Ethanediol with 1Butanol, 1-Hexanol, or 1-Octanol in the Temperature Range from 293.15 to 313.15. J. Mol. Liq. 2012, 168, 61-68.

(32) Zorębski, E.; Zorębski, M.; Ernst, S. Speed of Ultrasound in Liquids Measured at Constant Acoustic Path Length. Comparison and Discussion of Errors. J. Phys. IV 2005, 129, 79-82.

(33) Del Grosso, V. A.; Mader, C. W. Speed of Sound in Pure Water. J. Acoust. Soc. Am. 1972, 52, 1442-1446. 
(34) COSMOthermX Reference Manual, version C3.0, release 15.01; COSMOlogic GmbH \& Co. KG: Leverkusen, Germany, 2014.

(35) TURBOMOLE User's Manual, version 7.0; COSMOlogic GmbH \& Co. KG: Leverkusen, Germany, 2015.

(36) Schäfer, A.; Huber, C.; Ahlrichs, R. Fully Optimized Contracted Gaussian Basis Sets of Triple Zeta Valence Quality for Atoms Li to Kr. J. Chem. Phys. 1994, 100, 5829-5835.

(37) Weigend, F.; Häser, M. RI-MP2: First Derivatives and Global Consistency. Theor. Chem. Acc. 1997, 97, 331-340.

(38) COSMOconfX User Guide, version 3.0; COSMOlogic GmbH \& Co. KG: Leverkusen, Germany, 2013.

(39) Paulechka, Y. U. Heat Capacity of Room-Temperature Ionic Liquids: A Critical Review. J. Phys. Chem. Ref. Data 2010, 39, 033108.

(40) Fredlake, C. P.; Crosthwaite, J. M.; Hert, D. G.; Aki, S. N. V. K.; Brennecke, J. F. Thermo-Physical Properties of Imidazolium-Based Ionic Liquids. J. Chem. Eng. Data 2004, 49, 954-964.

(41) Makino, T.; Kanakubo, M.; Masuda, Y.; Mukaiyama, H. Physical and $\mathrm{CO}_{2}$-Absorption Properties of Imidazolium Ionic Liquids with Tetracyanoborate and Bis(trifluoromethanesulfonyl)amide Anions. J. Solution Chem. 2014, 43, 1601-1613.

(42) Troncoso, J.; Cerdeirina, C. A.; Sanmamed, Y. A.; Romani, L.; Rebelo, L. P. N. Thermodynamic Properties of Imidazolium-Based Ionic Liquids: Densities, Heat Capacities, and Enthalpies of Fusion of $[\mathrm{bmim}]\left[\mathrm{PF}_{6}\right]$ and $[\mathrm{bmim}]\left[\mathrm{NTf}_{2}\right]$. J. Chem. Eng. Data 2006, 51, 18561859.

(43) Shimizu, Y.; Ohte, Y.; Yamamura, Y.; Saito, K. Effects of Thermal History on Thermal Anomaly in Solid of Ionic Liquid Compound, $\left[\mathrm{C}_{4} \operatorname{mim}\right]\left[\mathrm{Tf}_{2} \mathrm{~N}\right]$. Chem. Lett. 2007, 36, 1484-1485.

(44) Blokhin, A. V.; Paulechka, Y. U.; Strechan, A. A.; Kabo, G. J. Physicochemical Properties, Structure, and Conformations of 1-Butyl3-methylimidazolium Bis(trifluoromethanesulfonyl) imide [ $\left.\mathrm{C}_{4} \mathrm{mim}\right]$ [NTf $\left.{ }_{2}\right]$ Ionic Liquid. J. Phys. Chem. B 2008, 112, 4357-4364.

(45) Shimizu, Y.; Ohte, Y.; Yamamura, Y.; Tsuzuki, S.; Saito, K. Comparative Study of Imidazolium- and Pyrrolidinium-Based Ionic Liquids: Thermodynamic Properties. J. Phys. Chem. B 2012, 116, 5406-5413.

(46) Zorębski, E.; Geppert-Rybczyńska, M.; Zorębski, M. Acoustic as a Tool for Better Characterization of Ionic Liquids: A Comparative Study of 1-Alkyl-3-methylimidazolium Bis[(trifluoromethyl)sulfonyl]imide Room-Temperature Ionic Liquids. J. Phys. Chem. B 2013, 117, 3867-3876.

(47) Nieto de Castro, C. A.; Langa, E.; Morais, A. L.; Matos Lopes, M. L.; Lourenço, M. J. V.; Santos, F. J. V.; Santos, M. S. C. S.; Canongia Lopes, J. N.; Veiga, H. I. M.; Macatrão, M.; Esperança, J. M. S. S.; Marques, C. S.; Rebelo, L. P. N.; Afonso, C. A. M. Studies on the Density, Heat Capacity, Surface Tension and Infinite Dilution Diffusion with the Ionic Liquids $\left[\mathrm{C}_{4} \mathrm{mim}\right]\left[\mathrm{NTf}_{2}\right],\left[\mathrm{C}_{4} \mathrm{mim}\right][\mathrm{DCA}]$, $\left[\mathrm{C}_{2} \mathrm{mim}\right]\left[\mathrm{EtOSO}_{3}\right]$ and [Aliquat][dca]. Fluid Phase Equilib. 2010, 294, $157-179$.

(48) Holbrey, J. D.; Reichert, M.; Reddy, R. G.; Rogers, R. D. Heat Capacities of Ionic Liquids and their Applications as Thermal Fluids. ACS Symp. Ser. 2003, 856, 121-133.

(49) Zhang, M.; Reddy, R. Application of $\left[\mathrm{C}_{4} \mathrm{~min}\right]\left[\mathrm{Tf}_{2} \mathrm{~N}\right]$ Ionic Liquid as Thermal Storage and Heat Transfer Fluids. ECS Trans. 2006, 2, 27-34.

(50) Hamidova, R.; Kul, I.; Safarov, J.; Shahverdiyev, A.; Hassel, E. Thermophysical Properties of 1-Butyl-3-Methylimidazolium Bis(trifluoromethylsulfonyl)Imide at High Temperatures and Pressures. Braz. J. Chem. Eng. 2015, 32, 303-316.

(51) Yamamuro, O.; Moriya, Y.; Inamura, Y. Glass Transitions and Low-Energy Excitations of Ionic Liquids. Netsu Sokutei 2007, 34, 120127.

(52) Paulechka, Y. U.; Blokhin, A. V.; Kabo, G. J.; Strechan, A. A. Thermodynamic Properties and Polymorphism of 1-Alkyl-3-methylimidazolium Bis(triflamides). J. Chem. Thermodyn. 2007, 39, 866-877. (53) Shimizu, Y.; Ohte, Y.; Yamamura, Y.; Saito, K. Is the Liquid or the Solid Phase Responsible for the Low Melting Points of Ionic Liquids? Alkyl-Chain-Length Dependence of Thermodynamic Properties of $\left[\mathrm{C}_{\mathrm{n}} \mathrm{mim}\right]\left[\mathrm{Tf}_{2} \mathrm{~N}\right]$. Chem. Phys. Lett. 2009, 470, 295-299.
(54) Waliszewski, D.; Stępniak, I.; Piekarski, H.; Lewandowski, A. Heat Capacities of Ionic Liquids and their Heats of Solution in Molecular Liquids. Thermochim. Acta 2005, 433, 149-152.

(55) Dzida, M.; Chorążewski, M.; Geppert-Rybczyńska, M.; Zorębski, E.; Zorębski, M.; Żarska, M.; Czech, B. Speed of Sound and Adiabatic Compressibility of 1-Ethyl-3-methylimidazolium Bis(trifluoromethylsulfonyl)imide under Pressures up to $100 \mathrm{MPa}$. J. Chem. Eng. Data 2013, 58, 1571-1576.

(56) Chirico, R. D.; Diky, V.; Magee, J. W.; Frenkel, M.; Marsh, K. N. Thermodynamics and Thermophysical Properties of the Reference Ionic Liquids: 1-Hexyl-3-methylimidazolium Bis(trifluoromethylsulfonyl)amide (Including Mixtures). Part 2. Critical Evaluation and Recommended Property Values. Pure Appl. Chem. 2009, 81, 791-828.

(57) Shimizu, Y.; Ohte, Y.; Yamamura, Y.; Saito, K.; Atake, T. LowTemperature Heat Capacity of Room-Temperature Ionic Liquid, 1Hexyl-3-methylimidazolium Bis(trifluoromethylsulfonyl)imide. J. Phys. Chem. B 2006, 110, 13970-13975.

(58) Blokhin, A. V.; Paulechka, Y. U.; Kabo, G. J. Thermodynamic Properties of $\left[\mathrm{C}_{6} \mathrm{mim}\right]\left[\mathrm{NTf}_{2}\right]$ in the Condensed State. J. Chem. Eng. Data 2006, 51, 1377-1388.

(59) Archer, D. G. Thermodynamic Properties of 1-Hexyl-3methylimidazolium Bis(trifluoromethylsulfonyl)imide; Internal Report6645; National Institute of Standards and Technology: Gaithersburg, MD, 2006.

(60) Bochmann, S.; Hefter, G. Isobaric Heat Capacities of the Ionic Liquids $\left[\mathrm{C}_{\mathrm{n}} \mathrm{mim}\right]\left[\mathrm{Tf}_{2} \mathrm{~N}\right](n=6,8)$ from $(323$ to 573$) \mathrm{K}$ at $10 \mathrm{MPa} . J$. Chem. Eng. Data 2010, 55, 1808-1813.

(61) Hughes, T. J.; Syed, T.; Graham, B. F.; Marsh, K. N.; May, E. F. Heat Capacities and Low Temperature Thermal Transitions of 1Hexyl and 1-Octyl-3-methylimidazolium Bis(trifluoromethylsulfonyl)amide. J. Chem. Eng. Data 2011, 56, 2153-2159.

(62) Diedrichs, A.; Gmehling, J. Measurement of Heat Capacities of Ionic Liquids by Differential Scanning Calorimetry. Fluid Phase Equilib. 2006, 244, 68-77.

(63) Paulechka, Y. U.; Kabo, A. G.; Blokhin, A. V.; Kabo, G. J.; Shevelyova, M. P. Heat Capacity of Ionic Liquids: Experimental Determination and Correlations with Molar Volume. J. Chem. Eng. Data 2010, 55, 2719-2724.

(64) González, B.; González, E. J. Physical Properties of the Pure 1Methyl-1-propylpyrrolidinium Bis(trifluoromethylsulfonyl)imide Ionic Liquid and its Binary Mixtures with Alcohols. J. Chem. Thermodyn. 2014, 68, 109-116.

(65) Jagadeeswara Rao, Ch.; Venkata Krishnan, R.; Venkatesan, K. A.; Nagarajan, K.; Srinivasan, T. G. Thermochemical Properties of Some Bis(trifluoromethylsulfonyl)imide Based Room Temperature Ionic Liquids. J. Therm. Anal. Calorim. 2009, 97, 937-943.

(66) Gardas, R. L.; Coutinho, J. A. P. A Group Contribution Method for Heat Capacity Estimation of Ionic Liquids. Ind. Eng. Chem. Res. 2008, 47, 5751-5757.

(67) Ge, R.; Hardacre, C.; Nancarrow, P.; Rooney, D. W. Thermal Conductivities of Ionic Liquids over the Temperature Range from 293 to 353 K. J. Chem. Eng. Data 2007, 52, 1819-1823.

(68) Tomida, D.; Kenmochi, S.; Tsukada, T.; Qiao, K.; Yokoyama, C. Thermal Conductivities of $[\mathrm{bmim}]\left[\mathrm{PF}_{6}\right],[\mathrm{hmim}]\left[\mathrm{PF}_{6}\right]$, and [omim]$\left[\mathrm{PF}_{6}\right]$ from 294 to $335 \mathrm{~K}$ at Pressures up to $20 \mathrm{MPa}$. Int. J. Thermophys. 2007, 28, 1147-1160.

(69) Fröba, A. P.; Rausch, M. H.; Krzeminski, K.; Assenbaum, D.; Wasserscheid, P.; Leipertz, A. Thermal Conductivity of Ionic Liquids: Measurement and Prediction. Int. J. Thermophys. 2010, 31, 20592077.

(70) Nieto de Castro, C. A.; Lourenço, M. J. V.; Ribeiro, A. P. C.; Langa, E.; Vieira, S. I. V.; Goodrich, P.; Hardacre, C. Thermal Properties of Ionic Liquids and IoNanofluids of Imidazolium and Pyrrolidinium Liquids. J. Chem. Eng. Data 2010, 55, 653-661.

(71) Gardas, R. L.; Ge, R.; Goodrich, P.; Hardacre, C.; Hussain, A.; Rooney, D. W. Thermophysical Properties of Amino Acid-Based Ionic Liquids. J. Chem. Eng. Data 2010, 55, 1505-1515. 
(72) Wu, K.-J.; Chen, Q.-L.; He, C.-H. Speed of Sound of Ionic Liquids: Database, Estimation, and its Application for Thermal Conductivity Prediction. AIChE J. 2014, 60, 1120-1131.

(73) Zorębski, E.; Piotrowska, M.; Dzida, M. Speed of Ultrasound and Internal Pressure of Propanediol and Butanodiol Isomers under Elevated Pressures. Acta Phys. Pol., A 2008, 114, A-265-A-270.

(74) Zorębski, E.; Dzida, M. The Effect of Temperature and Pressure on Acoustic and Thermodynamic properties of 1,4-Butanediol. The Comparison with 1,2-, and 1,3-Butanediols. J. Chem. Thermodyn. 2012, 54, 100-107.

(75) Zorębski, E. Internal Pressure Studies of Alcohols on the Basis of Ultrasonic Measurements. Mol. Quantum Acoust. 2005, 26, 317326.

(76) Marcus, Y. Internal Pressure of Liquids and Solutions. Chem. Rev. 2013, 113, 6536-6551.

(77) Zorębski, E. Effect of Temperature on Speed of Ultrasound and Adiabatic Compressibility of Binary Mixtures of 1,2-Ethanediol+1Pentanol. Mol. Quantum Acoust. 2004, 25, 291-296.

(78) Gibson, R. E.; Loefler, O. H. Pressure-Volume-Temperature Relation in Solutions. V. The Energy-Volume Coefficients of Carbon Tetrachloride, Water and Ethylene Glycol. J. Am. Chem. Soc. 1941, 63, 898-906.

(79) Blandmer, M. J.; Burgess, J.; Hakin, A. W. Internal Pressures, Temperatures of Maximum Density and Related Properties of Water and Deuterium Oxide. J. Chem. Soc., Faraday Trans. 1 1987, 83, 17831793.

(80) Zorębski, E.; Zorębski, M.; Dzida, M. Acoustic Nonlinearity Parameter B/A, Internal Presure, and Acoustic Impedance Determined at Pressures up to $100 \mathrm{MPa}$ for 1-Ethyl-3-methylimidazolium Bis [(trifluoromethyl)sulfonyl]imide. Arch. Acoust. 2016, 41, 59-66. 